\title{
Vacancies, Unemployment, and the Phillips Curve
}

\author{
Federico Ravenna and Carl E. Walsh*
}

June 16, 2007

PRELIMINARY

\begin{abstract}
The canonical new Keynesian Phillips Curve has become a standard component of models designed for monetary policy analysis. However, in the basic new Keynesian model, there is no unemployment, all variation in labor input occurs along the intensive hours margin, and the driving variable for inflation depends on workers' marginal rates of substitution between leisure and consumption. In this paper, we incorporate a theory of unemployment into the new Keynesian theory of inflation and empirically test its implications for inflation dynamics. We show how a traditional Phillips curve linking inflation and unemployment can be derived and how the elasticity of inflation with respect to unemployment depends on structural characteristics of the labor market such as the matching technology that pairs vacancies with unemployed workers. We estimate on US data the Phillips curve generated by the model, and derive the implied marginal cost measure driving inflation dynamics.
\end{abstract}

JEL: E52, E58, J64

\section{Introduction}

The canonical new Keynesian Phillips curve has become a standard component of models designed for monetary policy analysis. Based on the presence of monopolistic competition among individual firms, together with the imposition of stagged price setting, the new Keynesian Phillips curve provides a direct link between the underlying structural parameters characterizing the preferences of individual suppliers of labor and the parameters appearing in the Phillips curve.

\footnotetext{
${ }^{*}$ Department of Economics, University of California, Santa Cruz, CA 95064; fravenna@ucsc.edu, walshc@ucsc.edu. The authors would like to thank Michael Krause, Ricardo Lagos, Rob Valletta, John Williams and seminar participants at UC Irvine and at the Kiel Institute for the World Economy symposium on "The Phillips Curve and the Natural Rate of Unemployment" for helpful comments on an earlier version of this paper.
} 
However, in the basic new Keynesian model, all variation in labor input occurs along the intensive hours margin. In the standard sticky price, flexible wage model, the real wage and the marginal rate of substitution between leisure and consumption move together so that, at all points in time, households are supplying the amount of hours that maximize their utility, given the real wage. There are no unemployed workers; only hours worked per worker vary over the business cycle. As a consequence, the driving variable for inflation depends on workers' marginal rates of substitution between leisure and consumption. In its neglect of unemployment, the new Keynesian Phillips curve has a distinctly non-Keynesian flavor.

In contrast to this standard view of labor input, empirical evidence suggests that, at business cycle frequencies, most variation of labor input occurs at the extensive margin. In periods of below trend output, employed workers work fewer hours, but also fewer workers are employed. During periods of above trend output, employed workers work longer hours but also more workers are employed. These fluctuations in the fraction of workers actually employed reflect fluctuations in unemployment.

A growing number of papers have attempted to incorporate the extensive margin and unemployment into new Keynesian models. Examples include Walsh (2003, 2005), Alexopoulos (2004), Trigari (2004), Christoffel, Kuester, and Linzert (2006), Blanchard and Galí (2005, 2006), Krause and Lubik (2005), Barnichon (2006), Thomas (2006), and Gertler and Trigari (2006). The focus of these earlier contributions has extended from exploring the implications for macro dynamics in calibrated models to the estimation of DSGE models with labor market frictions.

In contrast to this earlier literature, we focus directly on the implications of the labor market specification for the Phillips curve and the connection between the structure of the labor market and the unemployment elasticity of inflation, and provide empirical testing of the model.

To draw a clear distinction with the previous literature, the basic version of our model allows labor to adjust only along the extensive margin. Standard models allow adjustment only along the intensive margin. Trigari (2004) and Thomas (2006) incorporate both margins, but marginal cost (and so inflation) is driven by the intensive margin. Consequently, the marginal rate of substitution between leisure hours and consumption is key, just as in standard new Keynesian models. Krause and Lubik depart from the Calvo model of price adjustment by assuming quadratic adjustment costs. In this case, all firms adjust each period, an implication that is not consistent with micro evidence on price adjustment. They also assume output adjustment occurs via fluctuations in the endogenous job destruction rate, which is not consistent with Hall's contention that this rate is roughly constant over the cycle. We retain the standard Calvo model of price adjustment and treat job destruction as exogenous.

Our empirical strategy lets us test equilibrium conditions that are consistent with a 
very large family of models incorporating labor market search frictions. While the most recent vintage of US data rejects the new Keynesian Phillips curve as a stable structural relationship, we show that the search-friction Phillips curve can potentially reconcile the new Keynesian model of inflation with the data. Our model predicts that the measure of marginal cost that drives inflation can be written in terms of labor market variables, as in the Keynesian tradition. We see this paper as providing a link between the much older literature on Phillips curves which related unemployment and inflation (e.g., Gordon 1976) and the modern approach based on dynamic stochastic general equilibrium models. The older literature investigated the connection between unemployment and inflation from an empirical perspective with little formal theory to link the two.

The rest of the paper is organizes as follows. The basic model is developed in section 2. A log-linearized version of the model is derived and the connections between labor market structure and the Phillip curve are discussed. Empirical estimates of the inflation equation in the presence of labor market frictions are provided in section 3. Conclusions are summarized in section 4 .

\section{The model economy}

The model consists of households whose utility depends on the consumption of market and home produced goods. Households members are either employed (in a match) or searching for a new match. This means that we do not focus on labor force participation decisions. Households are employed by wholesale goods producing firms operating in a competitive market for the goods they produce. Wholesale goods are, in turn, purchased by retail firms who sell to households. The retail goods market is characterized by monopolistic competition. In addition, retail firms have sticky prices that adjust according to a standard Calvo specification. The modelling strategy of locating labor market frictions in the wholesale sector where prices are flexible and locating sticky prices in the retail sector among firms who do not employ labor provides a convenient separation of the two frictions in the model. A similar approach was adopted in Walsh (2003, 2005), Trigari (2005), and Thomas (2006).

While we incorporate adjustment along both the intensive and extensive margin in the empirical model, we focus the theoretical discussion on a version containing only an extensive margin. This helps to isolate the role of unemployment fluctuations on inflation.

\subsection{Households}

Workers can be either employed by wholesale firms in production activities, receiving a market real wage $w_{t}$, or unemployed, earning a fixed amount $w^{u}$ of household production units. We assume that consumption risks are fully pooled; the consumption level of each worker would otherwise depend on its complete employment history. The optimality 
conditions for workers can be derived from the utility maximization problem of a large representative household with value function

$$
\begin{aligned}
W_{t}\left(N_{t}, B_{t}\right) & =\max \left\{U\left(C_{t}\right)+\beta E_{t} W_{t+1}\left(N_{t+1}, B_{t+1}\right)\right\} \\
\text { st } \quad P_{t} C_{t}+p_{b t} B_{t+1} & =P_{t}\left[w_{t} N_{t}+w^{u}\left(1-N_{t}\right)\right]+B_{t}+P_{t} \Pi_{t}^{r}
\end{aligned}
$$

where $C_{t}$ is consumption of each household's member, $N_{t}$ is the fraction of the household's members currently employed, $\Pi_{t}^{r}$ are profits from the retail sector, and $B_{t}$ is the amount of riskless nominal bonds held by the household with price equal to $p_{b t}$. The price of a unit of the consumption basket is $P_{t}$ and is defined below. Consumption of market goods supplied by the retail sector is equal to $C_{t}^{m}=C_{t}-\left(1-N_{t}\right) w^{u}$.

Consumption $C_{t}^{m}$ is an aggregate of goods purchased from the continuum of retail firms which produce differentiated final goods. The household preferences over the individual final goods from firm $j, C(j)$, are defined by the standard Dixit-Stiglitz aggregator, so that

$$
\begin{aligned}
E_{t}^{m} & =\int_{0}^{1} P_{t}(j) C_{t}^{m}(j) d j=P_{t} C_{t}^{m} \\
C_{t}^{m}(j) & =\left[\frac{P_{t}(j)}{P_{t}}\right]^{-\varepsilon} C_{t}^{m} \\
P_{t} & \equiv\left[\int_{0}^{1} P_{t}(j)^{1-\epsilon}\right]^{\frac{1}{1-\epsilon}},
\end{aligned}
$$

where $E_{t}^{m}$ is total expenditure by the household on consumption good purchases.

The intertemporal first order conditions yield the standard Euler equation:

$$
\lambda_{t}=\beta E_{t}\left\{R_{t} \lambda_{t+1}\right\}
$$

where $R_{t}$ is the gross return on an asset paying one unit of consumption aggregate in any state of the world and $\lambda_{t}$ is the marginal utility of consumption.

At the start of each period $t, N_{t-1}$ workers are matched in existing jobs. We assume a fraction $\rho(0 \leq \rho<1)$ of these matches exogenously terminate. To simplify the analysis, we ignore any endogenous separation. ${ }^{1}$ The fraction of the household members who are employed evolves according to

$$
N_{t}=(1-\rho) N_{t-1}+p_{t} s_{t}
$$

\footnotetext{
${ }^{1}$ Hall (2005) has argued that the separation rate varies little over the business cycle, although part of the literature disputes this position (see Davis, Haltiwanger and Schuh, 1996). For a model with endogenous separation and sticky prices, see Walsh (2003).
} 
where $p_{t}$ is the probability of a worker finding a position and

$$
s_{t}=1-(1-\rho) N_{t-1}
$$

is the fraction of searching workers. Thus, we assume workers displaced at the start of period $t$ have a probability $p_{t}$ of finding a new job within the period (we think of a quarter as the time period). Note that unemployment as measured after period $t$ hiring is equal to $u_{t} \equiv 1-N_{t}$.

\subsection{Wholesale firms and wages}

Production by wholesale firm $i$ is

$$
Y_{i t}^{w}=Z_{t} N_{i t},
$$

where $Z_{t}$ is a common, aggregate productivity disturbance with a mean equal to 1 and bounded below by zero. Aggregating (4), $Y_{t}^{w}=Z_{t} N_{t}$.

Wholesale firms must post vacancies to obtain new employees. They lose existing employees at the rate $\rho$. To post a vacancy, a wholesale firms must pay a cost $P_{t} \kappa$ for each job posting. Since job postings are homogenous with final goods, effectively wholesale firms solve a static problem symmetric to the household's one: they buy individual final goods $v_{t}(j)$ from each $j$ final-goods-producing retail firm so as to minimize total expenditure, given that the production function of a unit of final good aggregate $v_{t}$ is given by

$$
\left[\int_{0}^{1} v_{t}(j)^{\frac{\varepsilon-1}{\varepsilon}} d z\right]^{\frac{\varepsilon}{\varepsilon-1}} \geq v_{t} .
$$

Therefore, total expenditures $E^{w}$ on job postings and the demand by wholesale firms for the final goods produced by retail firm $j$ are given by

$$
\begin{aligned}
E_{t}^{w} & =\kappa \int_{0}^{1} P_{t}(j) v_{t}(j) d j=\kappa P_{t} v_{t} \\
v_{t}(j) & =\left[\frac{P_{t}(j)}{P_{t}}\right]^{-\varepsilon} v_{t},
\end{aligned}
$$

where, as before, $P_{t}=\left[\int_{0}^{1} P_{t}(j)^{1-\epsilon}\right]^{\frac{1}{1-\epsilon}}$.

Total expenditure on final goods by households and wholesale firms is 


$$
\begin{aligned}
E_{t} & =E_{t}^{m}+E_{t}^{w} \\
& =\int_{0}^{1} P_{t}(j) C_{t}^{m}(j) d j+\kappa \int_{0}^{1} P_{t}(j) v_{t}(j) d j \\
& =\int_{0}^{1} P_{t}(j) Y_{t}^{d}(j) d j \\
& =P_{t}\left(C_{t}^{m}+\kappa v_{t}\right)
\end{aligned}
$$

where $Y_{t}^{d}(j)=C_{t}^{m}(j)+\kappa v_{t}(j)$ is total demand for final good $j$.

The number of workers available for production at firm $i$ is given by

$$
N_{i t}=(1-\rho) N_{i t-1}+v_{i t} q\left(\theta_{t}\right)
$$

where $v_{i t}$ is the number of vacancies the firm posts and $q\left(\theta_{t}\right)$ is the probability of filling a vacancy. We assume the matching function displays constant returns to scale in vacancies and searching workers, so the probability $q$ is a function of aggregate labor market tightness $\theta_{t}$, equal to the ratio of aggregate vacancies $v_{t}$ and the aggregate number of workers searching for a job $s_{t}\left(\theta_{t} \equiv v_{t} / s_{t}\right)$. At the aggregate level, workers available for production in period $t$ equal

$$
N_{t}=(1-\rho) N_{t-1}+v_{t} q\left(\theta_{t}\right)
$$

Wholesale firms sell their output in a competitive market at the price $P_{t}^{w}$. The real value of the firm's output, expressed in terms of time $t$ consumption goods, is $P_{t}^{w} Y_{i t} / P_{t}=$ $Y_{i t} / \mu_{t}$, where $\mu_{t}=P_{t} / P_{t}^{w}$ is the markup of retail over wholesale prices.

Let $\Pi_{i t}$ denote firm $i$ 's period $t$ profit. The wholesale firm's problem is to maximize

$$
E_{t} \sum_{j=0}^{\infty} \beta^{j}\left(\frac{\lambda_{t+i}}{\lambda_{t}}\right) \Pi_{i t+j},
$$

where

$$
\Pi_{i t+j}=\mu_{t+i}^{-1} Y_{i t+j}^{w}-\kappa v_{i t+j}-w_{t+j} N_{i t+j}
$$

and the maximization is subject to (4) and (6) and is with respect to $Y_{i t}^{w}, N_{i t}$, and $v_{i t}$. Let $\psi$ and $\varphi$ be the Lagrangian multipliers on (4) and (6). Then the first order conditions for the firm's problem are

$$
\text { For } Y_{i t}^{w}: \mu_{t}^{-1}-\psi_{i t}=0
$$

For $v_{i t}:-\kappa-\varphi_{i t} q\left(\theta_{t}\right)=0$

For $N_{i t}: \mu_{t}^{-1} Z_{t}-w_{t}+\varphi_{i t}-\beta(1-\rho) E_{t}\left(\frac{\lambda_{t+1}}{\lambda_{t}}\right) \varphi_{i t+1}=0$ 
The first two of these conditions imply

$$
\psi_{i t}=\psi_{t}=\left(\frac{1}{\mu_{t}}\right) \text { for all } t
$$

and

$$
\varphi_{i t}=-\frac{\kappa}{q\left(\theta_{t}\right)} \text { for all } t .
$$

Thus, reflecting the competitive market for the output of wholesale firms, each such firm charges the same price and the shadow price of a filled job is equal across firms.

Using these results in the last first order condition yields

$$
\frac{\kappa}{q\left(\theta_{t}\right)}=\frac{Z_{t}}{\mu_{t}}-w_{t}+\beta(1-\rho) E_{t}\left(\frac{\lambda_{t+1}}{\lambda_{t}}\right) \frac{\kappa}{q\left(\theta_{t+1}\right)} .
$$

We can rewrite this equation as

$$
w_{t}=\frac{Z_{t}}{\mu_{t}}-\frac{\kappa}{q\left(\theta_{t}\right)}+\beta(1-\rho) E_{t}\left(\frac{\lambda_{t+1}}{\lambda_{t}}\right) \frac{\kappa}{q\left(\theta_{t+1}\right)}
$$

The real wage is equal to the marginal product of labor $Z_{t} / \mu_{t}$, minus the expected cost of hiring the matched worker $\kappa / q\left(\theta_{t}\right)$ (a vacancy is matched with probability $q\left(\theta_{t}\right)$, so the number of vacancies to be posted such that expected hires equals one is $1 / q\left(\theta_{t}\right)$, each of which costs $\kappa$ ), plus the expected saving the following period of not having to generate a new match, all expressed in units of the final good. Note that if $\kappa=0$, this yields the standard result that $w_{t}=Z_{t} / \mu_{t}$.

The value of a filled job is equal to $\kappa / q\left(\theta_{t}\right)$. To see this, let $V_{t}^{V}$ and $V_{t}^{J}$ be the value to the firm of an unfilled vacancy and a filled job respectively. Then

$$
V_{t}^{V}=-\kappa+q\left(\theta_{t}\right) V_{t}^{J}+\left[1-q\left(\theta_{t}\right)\right] E_{t} \beta\left(\frac{\lambda_{t+1}}{\lambda_{t}}\right) V_{t+1}^{V} .
$$

Free entry implies that $V_{t}^{V}=0$, so

$$
V_{t}^{J}=\frac{\kappa}{q\left(\theta_{t}\right)}
$$

\subsubsection{Wages}

Assume the wage is set in Nash bargaining with the worker's share equal to $b$. Let $V_{t}^{S}$ be the surplus to the worker of being matched to a firm relative to not being in a match. Then the outcome of the wage bargain ensures

$$
(1-b) V_{t}^{S}=b V_{t}^{J}=\frac{b \kappa}{q\left(\theta_{t}\right)}
$$


where the job posting condition (8) has been used. Since the probability of a searching worker being employed is $p_{t}=M_{t} / s_{t}=\theta_{t} q\left(\theta_{t}\right)$ where $M_{t}$ is the number of new employerworker matches formed in $t$, the value of the match to the worker can be rewritten as

$$
V_{t}^{S}=w_{t}-w^{u}+\beta(1-\rho) E_{t}\left(\frac{\lambda_{t+1}}{\lambda_{t}}\right)\left[1-\theta_{t+1} q\left(\theta_{t+1}\right)\right] V_{t+1}^{S}
$$

The term $\left[1-\theta_{t+1} q\left(\theta_{t+1}\right)\right]$ arises since workers who are in a match at time $t$ but who do not survive the exogenous separation hazard at $t+1$ may find a new match during $t+1 .^{2}$

Using (10) in (9),

$$
\frac{b \kappa}{q\left(\theta_{t}\right)}=(1-b)\left(w_{t}-w^{u}\right)+\beta(1-\rho) E_{t}\left(\frac{\lambda_{t+1}}{\lambda_{t}}\right)\left[1-\theta_{t+1} q\left(\theta_{t+1}\right)\right] \frac{b \kappa}{q\left(\theta_{t+1}\right)} .
$$

Solving for the wage and substituting the result into (7), one obtains an expression for the real wage:

$$
w_{t}=(1-b) w^{u}+b\left[\frac{Z_{t}}{\mu_{t}}+\beta(1-\rho) E_{t}\left(\frac{\lambda_{t+1}}{\lambda_{t}}\right) \kappa \theta_{t+1}\right] .
$$

Substituting (11) into (7), one finds that the relative price of wholesale goods in terms of retail goods is equal to

$$
\frac{P_{t}^{w}}{P_{t}}=\frac{1}{\mu_{t}}=\frac{\tau_{t}}{Z_{t}}
$$

where

$$
\tau_{t} \equiv w^{u}+\left(\frac{1}{1-b}\right)\left\{\frac{\kappa}{q\left(\theta_{t}\right)}-\beta(1-\rho) E_{t}\left(\frac{\lambda_{t+1}}{\lambda_{t}}\right)\left[1-b \theta_{t+1} q\left(\theta_{t+1}\right)\right] \frac{\kappa}{q\left(\theta_{t+1}\right)}\right\}
$$

summarizes the impact of labor market conditions on the relative price variable.

It is useful to contrast expression (12) with the corresponding expression arising in a new Keynesian model with a Walrasian labor market. The marginal cost faced by a retail firm is $P_{t}^{w} / P_{t}$. In a standard new Keynesian model with sticky prices, marginal cost is proportional to the ratio of the marginal rate of substitution between leisure and consumption (equal to the real wage) and the marginal product of labor. Since the marginal product of labor is equal to $Z_{t}$, (12) shows how, in a search model of the labor market, the marginal rate of substitution is replaced by a labor-cost expression that depends on the worker's outside productivity, $w^{u}$, and current and expected future labor market conditions via $\theta_{t}$ and $\theta_{t+1}$. If vacancies could be posted costlessly $(\kappa=0)$, then $\tau_{t}=w^{u}$ as firms only need to pay workers a wage equal to worker's outside opportunity. When $\kappa>0$, matches have an asset value and the wage will exceed $w^{u}$. The wage, and therefore marginal cost, varies with labor market tightness.

\footnotetext{
${ }^{2}$ See the appendix for details.
} 


\subsection{Retail firms}

Each retail firm purchases wholesale output which it converts into a differentiated final good sold to households and wholesale firms. The retail firms cost minimization problem implies

$$
M C_{t}^{n}=P_{t} M C_{t}=P_{t}^{w}
$$

where $M C^{n}$ is nominal marginal cost and $M C$ is real marginal cost.

Retail firms adjust prices according to the Calvo updating model. Each period a firm can adjust its price with probability $1-\omega$. Since all firms that adjust their price are identical, they all set the same price. Given $M C_{t}^{n}$, the retail firm chooses $P_{t}(j)$ to maximize

$$
\sum_{i=0}^{\infty}(\omega \beta)^{i} E_{t}\left[\left(\frac{\lambda_{t+i}}{\lambda_{t}}\right) \frac{P_{t}(j)-M C_{t+i}^{n}}{P_{t+i}} Y_{t+i}(j)\right]
$$

subject to

$$
Y_{t+i}(j)=Y_{t+i}^{d}(j)=\left[\frac{P_{t}(j)}{P_{t+i}}\right]^{-\varepsilon} Y_{t+i}^{d}
$$

where $Y_{t}^{d}=\frac{E_{t}}{P_{t}}$ is aggregate demand for the final goods basket. The standard pricing equation obtains. These can be written as

$$
\left[\left(1+\pi_{t}\right)\right]^{1-\varepsilon}=\omega+(1-\omega)\left[\frac{\tilde{G}_{t}}{\tilde{H}_{t}}\left(1+\pi_{t}\right)\right]^{1-\varepsilon},
$$

where

$$
\begin{gathered}
\tilde{G}_{t}=\mu \lambda_{t} \mu_{t}^{-1} Y_{t}+\omega \beta \tilde{G}_{t+1}\left(1+\pi_{t+1}\right)^{\varepsilon} \\
\tilde{H}_{t}=\lambda_{t} Y_{t}+\omega \beta \tilde{H}_{t+1}\left(1+\pi_{t+1}\right)^{\varepsilon-1}
\end{gathered}
$$

and $\lambda_{t}$ is the marginal utility of consumption.

\subsection{Market Clearing}

Aggregating the budget constraint (1) over all households yields

$$
P_{t} C_{t}^{m}=P_{t} w_{t} N_{t}+P_{t} \Pi_{t}^{r}
$$

Since the wholesale sector is in perfect competition, profits $\Pi_{i t}$ are zero for each $i$ firm and

$$
\frac{P_{t}^{w}}{P_{t}} Y_{t}^{w}=w_{t} N_{t}+\kappa v_{t}
$$

In turn, this implies

$$
C_{t}^{m}=\frac{P_{t}^{w}}{P_{t}} Y_{t}^{w}-\kappa v_{t}+\Pi_{t}^{r}
$$


Profits in the retail sector are equal to

$$
\begin{aligned}
\Pi_{t}^{r} & =\int\left[\frac{P_{t}(j)}{P_{t}}-\frac{P_{t}^{w}}{P_{t}}\right] Y_{t}^{d}(j) d j \\
& =\frac{1}{P_{t}} \int P_{t}(j) Y_{t}^{d}(j) d j-\frac{P_{t}^{w}}{P_{t}} \int Y_{t}^{d}(j) d j
\end{aligned}
$$

Since for each good $j$ market clearing implies $Y_{t}^{d}(j)=Y_{t}(j)$, and since the production function of final goods is given by $Y_{t}(j)=Y_{t}^{w}(j)$, we can write profits of the retail sector as

$$
\Pi_{t}^{r}=Y_{t}^{d}-\frac{P_{t}^{w}}{P_{t}} Y_{t}^{w}
$$

where $Y_{t}^{w}=\int Y_{t}^{w}(j) d j$. Using this result, eq. (16) gives aggregate real spending:

$$
Y_{t}^{d}=C_{t}^{m}+\kappa v_{t}
$$

Finally, using the demand for final good $j$ in (14), the aggregate resource constraint is

$$
\begin{aligned}
\int Y_{t}(j) d j & =\int Y_{t}^{w}(j) d j=Z_{t} \int N_{t}(j) d j=Z_{t} N_{t} \\
& =\int\left[\frac{P_{t}(j)}{P_{t}}\right]^{-\varepsilon} Y_{t}^{d} d j=\int\left[\frac{P_{t}(j)}{P_{t}}\right]^{-\varepsilon}\left[C_{t}^{m}+\kappa v_{t}\right] d j
\end{aligned}
$$

or

$$
Y_{t}^{w}=Z_{t} N_{t}=\left[C_{t}^{m}+\kappa v_{t}\right] \int\left[\frac{P_{t}(j)}{P_{t}}\right]^{-\varepsilon} d j
$$

Aggregate consumption is given by

$$
C_{t}=C_{t}^{m}+w^{u}\left(1-N_{t}\right)
$$

A more compact way of rewriting the resource constraint can be obtained by writing (17) and (18) as:

$$
\begin{aligned}
Y_{t}^{d} & =C_{t}^{m}+\kappa v_{t} \\
Y_{t}^{w} & =Y_{t}^{d} f_{t},
\end{aligned}
$$

where $f_{t}$ is defined as

$$
f_{t} \equiv \int_{0}^{1}\left[\frac{P_{t}(z)}{P_{t}}\right]^{-\varepsilon} d z
$$

and measures relative price dispersion across retail firms. 


\subsection{Equilibrium with sticky prices}

When prices are sticky $(\omega>0)$, the retail price markup (equivalently, the marginal cost of retail firms) can vary. The complete set of equilibrium conditions is given by

$$
\begin{gathered}
C_{t}^{-\sigma}=\beta E_{t}\left\{R_{t} C_{t+1}^{-\sigma}\right\} \\
\frac{Z_{t}}{\mu_{t}}=w^{u}+\frac{1}{1-b} \kappa \frac{1}{\eta} \theta_{t}^{1-\xi}-\kappa \beta\left(\frac{1-\rho}{1-b}\right) E_{t}\left(\frac{C_{t+1}}{C_{t}}\right)^{-\sigma}\left(\frac{1}{\eta} \theta_{t+1}^{-\xi}-b\right) \theta_{t+1} . \\
C_{t}=Z_{t} N_{t}+\left[w^{u}\left(1-\eta \theta_{t}^{\xi}\right)-\kappa \theta_{t}\right] s_{t} \\
N_{t}=(1-\rho) N_{t-1}+\eta \theta_{t}^{\xi}\left[1-(1-\rho) N_{t-1}\right] \\
s_{t}=1-(1-\rho) N_{t-1} \\
Z_{t} N_{t}=Y_{t} \int_{0}^{1}\left[\frac{P_{t}(z)}{P_{t}}\right]^{-\varepsilon} d z \\
Y_{t}=C_{t}-w^{u}\left(1-N_{t}\right)+\kappa s_{t} \theta_{t} \\
{\left[\left(1+\pi_{t}\right)\right]^{1-\varepsilon}=\omega+(1-\omega)\left[\frac{\tilde{G}_{t}}{\tilde{H}_{t}}\left(1+\pi_{t}\right)\right]^{1-\varepsilon}} \\
\tilde{G}_{t}=\mu \lambda_{t} \mu_{t}^{-1} Y_{t}+\omega \beta \tilde{G}_{t+1}\left(1+\pi_{t+1}\right)^{\varepsilon} \\
\tilde{H}_{t}=\lambda_{t} Y_{t}+\omega \beta \tilde{H}_{t+1}\left(1+\pi_{t+1}\right)^{\varepsilon-1}
\end{gathered}
$$

and a specification for monetary policy.

\subsection{Log linearization of the Phillips Curve}

The standard new Keynesian Phillips Curve is obtained by log-linearizing the price adjustment equation. A comparable Phillips Curve consistent with the model of labor market frictions can also be obtained. We begin by collecting the equilibrium conditions in the presence of sticky prices and then derive the log-linearized Phillips Curve.

Let $\hat{x}_{t}$ denote the log deviation of a variable $x$ around its steady-state value, and let $\tilde{x}_{t}$ denote the deviation of $\hat{x}_{t}$ around its flexible-price equilibrium value. A variable without a time subscript denotes a steady-state value. Using (20), (26) - (28) results in the following expressions for inflation and real marginal cost:

$$
\pi_{t}=\beta E_{t} \pi_{t+1}-\delta \hat{\mu}_{t}
$$




$$
\begin{aligned}
\mu_{t}= & z_{t}-A(1-\xi) \hat{\theta}_{t} \\
& -A \beta(1-\rho)[1-b \theta q(\theta)] E_{t}\left(i_{t}-E_{t} \pi_{t+1}\right) \\
& +A \beta(1-\rho)[1-\xi-b \theta q(\theta)] E_{t} \hat{\theta}_{t+1},
\end{aligned}
$$

where

$$
\delta \equiv \frac{(1-\omega)(1-\omega \beta)}{\omega}
$$

and

$$
A \equiv \mu\left(\frac{1}{1-b}\right) \frac{\kappa}{q(\theta)} .
$$

The expressions for inflation and the markup illustrate how labor market tightness affects inflation. A rise in labor market tightness reduces the retail price markup, increasing the marginal cost of the retail firms. This leads to a rise in inflation. Expected future labor market tightness also affects current inflation. For a given $\hat{\theta}_{t}$, a rise in $E_{t} \hat{\theta}_{t+1}$ increases the markup and reduces current inflation. ${ }^{3}$ It does so through its effects on current wages. Expectations of labor market tightness increase the incentive of firms to post vacancies. This would normally lead to a rise in current tightness. However, since the coefficient on $E_{t} \hat{\theta}_{t+1}$ measures the impact on $\mu_{t}$ when $\hat{\theta}_{t}$ remains constant, wages must fall to offset the rise in vacancies that would otherwise occur and keep $\hat{\theta}_{t}$ constant. Finally, there is a cost channel effect in that the real interest rate has a direct impact on $\mu_{t}$ and therefore on inflation. This arises since it is the present discounted value of expected future labor market conditions that matter.

We can further simplify the system of equations to obtain a form more easily comparable to the standard new Keynesian model. Noting that $\hat{n}_{t}=-\left(\frac{1-N}{N}\right) \hat{u}_{t}$ and $s_{t}=\left(\frac{1-s}{s}\right)\left(\frac{1-N}{N}\right) \hat{u}_{t-1}$, eq. (22) describing the evolution of employment can be expressed as

$$
\hat{\theta}_{t}=-\left(\frac{1-N}{N}\right)\left(\frac{1}{\rho \xi}\right)\left[\hat{u}_{t}-(1-\rho)[1-\theta q(\theta)] \hat{u}_{t-1}\right] .
$$

Using (29), the expression for the price markup becomes

$$
\mu_{t}=z_{t}+h_{1} \hat{u}_{t}-h_{2} \hat{u}_{t-1}-h_{3} E_{t} \hat{u}_{t+1}-h_{4}\left(i_{t}-E_{t} \pi_{t+1}\right)
$$

where

$$
\begin{gathered}
h_{1}=B\left\{1+\beta(1-\rho)\left[1-\frac{b \theta q(\theta)}{1-\xi}\right][1-\theta q(\theta)]\right\} \\
h_{2}=B[1-\theta q(\theta)]>0 \\
h_{3}=\beta B\left[1-\frac{b \theta q(\theta)}{1-\xi}\right] \\
h_{4}=\beta A(1-\rho)[1-b \theta q(\theta)]>0,
\end{gathered}
$$

\footnotetext{
${ }^{3}$ In our baseline calibration, $1-\xi-b \theta q(\theta)>0$.
} 
and

$$
B \equiv A\left(\frac{u}{N}\right)\left(\frac{1-\rho}{\rho}\right)\left(\frac{1-\xi}{\xi}\right) .
$$

Using this expression for the markup in the inflation adjustment equation yields a new Keynesian Phillips curve expressed in terms of expected future inflation, unemployment, lagged unemployment, expected future unemployment, and the real rate of interest:

$$
\pi_{t}=\beta E_{t} \pi_{t+1}-\delta h_{1} \hat{u}_{t}+\delta h_{2} \hat{u}_{t-1}+\delta h_{3} E_{t} \hat{u}_{t+1}+\delta h_{4}\left(i_{t}-E_{t} \pi_{t+1}\right)-\delta z_{t} .
$$

Equation (31) provides the new Keynesian Phillips Curve in the presence of labor market search frictions. Three important differences are apparent. First, inflation depends on both expected future unemployment and lagged unemployment. Therefore the model (depending on the parameterization) is able to generate endogenous inflation persistence. Second, all the coefficients in the equation depend on the structural parameters that characterize the labor market. In the standard new Keynesian model, they depend only on preference parameters from the representative agent's utility function and the degree of nominal price rigidity. Third, there is a real cost channel in that the real interest rate has a direct impact on inflation. This will affect the impact of monetary policy by generating a supply-side channel through which monetary policy affects inflation (see Ravenna and Walsh 2006).

\subsection{Unemployment and the Phillips Curve}

In this section, we investigate the dependence of the unemployment-inflation relationship on labor market frictions. Rewrite eq. (31) as:

$$
\pi_{t}=\beta E_{t} \pi_{t+1}-\tilde{h}_{1} \hat{u}_{t}+\tilde{h}_{2} \hat{u}_{t-1}+\tilde{h}_{3} E_{t} \hat{u}_{t+1}+\tilde{h}_{4} E_{t}\left(i_{t}-E_{t} \pi_{t+1}\right)-\delta z_{t}
$$

where $\tilde{h}_{i}=\delta h_{i}$. The coefficients on current, lagged, and future unemployment in this equation reflect the impact of unemployment on inflation, holding the real interest rate constant. ${ }^{4}$ In our parameterization, the coefficients on $\hat{u}_{t-1}$ and $E_{t} \hat{u}_{t+1}$ are small relative to the coefficient on $\hat{u}_{t}$ and these coefficients are relatively insensitive to the parameter variations we consider below. Thus, we focus on $\tilde{h}_{1}$ in (32).

\footnotetext{
${ }^{4}$ The real interest and unemployment are linked by the equilibrium conditions (19) to (25). Using these conditions, we can obtain an inflation equaton that accounts for the movements of the real rate of interest necessary to be consistent with the path of the unemployment gap - that is, accounts for the cost channel implications of movements in $\hat{u}_{t}$ (see Ravenna and Walsh, 2007). For the parameterizations discussed in the next subsection, this general equilibrium effect is small and does not affect quantitatively the results.
} 


\subsubsection{Parameterization}

The baseline values for the model parameters are given in the Table below. All of these are standard in the literature. We impose the Hosios condition by setting $b=1-\xi$. By calibrating the steady-state job finding probability $q$ and the replacement ratio $\phi \equiv w^{u} / w$ directly, we can use steady-state conditions to solve for the job posting cost $\kappa$ and the reservation wage $w^{u} \cdot{ }^{5}$ Given the parameters in the Table, the remaining parameters and the steady-state values needed to obtain the log-linear approximation can be calculated.

\begin{tabular}{|lll|}
\hline \multicolumn{3}{|c|}{ Table: Parameter Values } \\
\hline \hline Exogenous separation rate & $\rho$ & 0.1 \\
Vacancy elasticity of matches & $\xi$ & 0.4 \\
Workers' share of surplus & $b$ & 0.6 \\
Replacement ratio & $\phi$ & 0.4 \\
Vacancy filling rate & $q$ & 0.7 \\
Labor force & $N$ & 0.95 \\
Discount factor & $\beta$ & 0.99 \\
Relative risk aversion & $\sigma$ & 2 \\
Markup & $\mu$ & 1.2 \\
Price adjustment probability & $1-\omega$ & 0.75 \\
\hline
\end{tabular}

\subsubsection{Results}

In this section, we explore the effects of the probability of exogenous separation, labor's share of the match surplus, and the job finding probability on the unemployment elasticity of inflation.

Figure 1 plots $\tilde{h}_{1}$ as a function of $\rho$. As $\rho$ increases, the elasticity of employment (and unemployment) with respect to $\theta$ rises. With fewer matches surviving from one period to the next, the share of new matches in total employment increases, making employment more sensitive to labor market conditions. Conversely, a given change in unemployment is associated with a smaller change in $\theta$ and, consequentiality, in retail firm's marginal cost. Inflation becomes less sensitive to unemployment. In addition, the role of past labor

\footnotetext{
${ }^{5}$ To find $\kappa$ and $w^{u}$, assume $w^{u}=\phi w$, where $\phi$ is the wage replacement rate. Then equilibrium in the steady state implies

$$
\begin{gathered}
{[1-\phi(1-b)] w^{u}=\phi b\left[\frac{1}{\mu}+(1-\rho) \beta \kappa \theta\right]} \\
\left\{[1-\beta(1-\rho)] \eta^{-1} \bar{\theta}^{1-\xi}+b \beta(1-\rho) \bar{\theta}\right\} \kappa=(1-b)\left(\frac{1}{\mu}-w^{u}\right)
\end{gathered}
$$
}

and these two equations can be jointly solved for $\kappa$ and $w^{u}$. That is,

$$
\left[\begin{array}{c}
w^{u} \\
\kappa
\end{array}\right]=\left[\begin{array}{cc}
1-\phi(1-b) & -\phi b(1-\rho) \beta \theta \\
1-b & {[1-\beta(1-\rho)] \eta^{-1} \bar{\theta}^{1-\xi}+b \beta(1-\rho) \bar{\theta}}
\end{array}\right]^{-1}\left[\begin{array}{c}
\frac{\phi b}{\mu} \\
\frac{1-b}{\mu}
\end{array}\right]
$$


market conditions falls as match duration declines, and this also reduces the impact of unemployment on expected future marginal cost and inflation.

Under Nash bargaining, the dynamics of unemployment and inflation are affected by the respective bargaining power of workers and firms. Figure 2 illustrates the impact of labor's share of the match surplus, $b$, on the responsiveness of inflation to unemployment. As labor's share of the surplus rises, the incentive to create new jobs falls. An expansion of output must be associated with a larger rise in the price of wholesale goods relative to retail goods if wholesale firms are to increase production. Thus, the marginal cost to the retail firms, and retail price inflation, becomes more responsive to unemployment movements as $b$ increases.

The last exercise we examine is the impact of the probability of filling a job on the Phillips curve. In the baseline calibration, we set the steady-state probability of filling a vacancy equal to 0.7 . In absolute value, the impact of unemployment on inflation declines with the steady-state value of $q(\theta)$ (figure 3 ). The steady-state value of a filled job falls as the steady-state probability of filling a vacancy rises. The effect a fall in the value of a filled job has on inflation can be inferred from eqs. (12) and (13). As $\kappa / q(\theta)$ becomes smaller, the marginal cost of labor to wholesale firms approaches the fixed opportunity wage $w^{u}$. In the extreme case with $\tau=w^{u}$, eq. (12) implies that the price markup variable $\mu$ would be constant and equal to $Z_{t} / w^{u}$. This corresponds to the case of a perfectly elastic supply of labor to wholesale firms. A demand expansion leads to a fall in unemployment but no increase in the price of wholesale goods relative to retail goods. Thus, the marginal cost faced by retail firms would remain constant, as would inflation.

\section{Empirical Estimates of the Inflation Equation}

The introduction of search frictions and unemployment in the New Keynesian model has profound implications for the driving variable of the inflation process. A vast literature debated the relative advantages of alternative marginal cost measures as an indicator of the business cycle and of inflationary pressure (Rotemberg and Woodford, 1999, Rudd and Whelan, 2005). Our model contributes to this literature since it predicts that the measure of marginal cost that drives inflation can be written in terms of labor market variables, as in the Keynesian tradition. In addition, the estimation of the inflation equation provides a straightforward test of the relevance of search frictions for macroeconomic volatility.

As in the baseline New Keynesian model, the inflation equation is given by:

$$
\begin{aligned}
\pi_{t} & =\beta E_{t} \pi_{t+1}+\delta \widehat{m c}_{t} \\
\delta & =\frac{(1-\omega)(1-\beta \omega)}{\omega}
\end{aligned}
$$


The real marginal cost variable will depend both on the variable cost of employing a labor match in production, and on the asset value of the match, which changes over the business cycle. Eq. (7) implies wholesale firms equate the revenue from entering into one additional productive match $M R_{t}^{\text {wholesale }}=1 / \mu_{t}$ to its marginal cost (expressed in levels and in final good consumption units):

$$
M C_{t}=\frac{1}{f_{t}^{\prime}}\left\{w_{t}+\frac{\kappa}{q\left(\theta_{t}\right)}-(1-\rho) E_{t} \beta\left(\frac{\lambda_{t+1}}{\lambda_{t}}\right) \frac{\kappa}{q\left(\theta_{t+1}\right)}\right\},
$$

where $f_{t}^{\prime}=\partial Z_{t} N_{t} / \partial N_{t}$. Since the marginal revenue of wholesale firms is the marginal cost of retail firms, $M R_{t}^{\text {wholesale }}=1 / \mu_{t}=M C_{t}^{\text {retail }}$. The variable $\tau_{t}$ :

$$
\tau_{t} \equiv \frac{Z_{t}}{\mu_{t}}=w_{t}+\frac{\kappa}{q\left(\theta_{t}\right)}-(1-\rho) E_{t} \beta\left(\frac{\lambda_{t+1}}{\lambda_{t}}\right) \frac{\kappa}{q\left(\theta_{t+1}\right)}
$$

can be interpreted as the marginal cost of entering into a match (in consumption units), that is, the marginal cost of having one productive unit of labor installed. The marginal cost of producing one unit of output is equal to the marginal cost of entering into a match divided by the marginal product of the match:

$$
\frac{1}{\mu_{t}}=M C_{t}=\frac{\tau_{t}}{Z_{t}}
$$

The forcing variable in the inflation equation can also be obtained by using eq. (34) and the equilibrium condition for wage bargaining, which gives eq. (13), rewritten here for convenience:

$$
\tau_{t}=w^{u}+\left(\frac{1}{1-b}\right)\left\{\frac{\kappa}{q\left(\theta_{t}\right)}-\beta(1-\rho) E_{t}\left(\frac{\lambda_{t+1}}{\lambda_{t}}\right)\left[1-b \theta_{t+1} q\left(\theta_{t+1}\right)\right] \frac{\kappa}{q\left(\theta_{t+1}\right)}\right\}
$$

Finally, using the remaining first order and market clearing conditions eq.(31) implies a third definition of $M C_{t}$ given by the log-linear relation:

$$
\widehat{m c}_{t}=-h_{1} \hat{u}_{t}+h_{2} \hat{u}_{t-1}+h_{3} E_{t} \hat{u}_{t+1}+h_{4}\left(i_{t}-E_{t} \pi_{t+1}\right)-\widehat{f}_{t}^{\prime}
$$

There are two advantages in using the definition in eq. (33) rather than the one in (35) or (36) to estimate the inflation equation. First, both eqs. (35) and (36) impose a far larger number of theoretical restrictions on the data generating process. For example, the equilibrium condition for $\tau_{t}$ in eq. (35) requires not only that the firms' first order condition is correctly specified, but also that the household's preferences and the bargaining process appropriately describe the data. As a first step, it seems reasonable to test the inflation equation without taking a stand on the household preferences and the wage-setting mechanism.

Second, the functional form of eq. (33) is unchanged if an intensive margin is in- 
troduced in the model. The model outlined in the preceding section implicitly assumes a very high elasticity of the household's utility to changes in the amount of per-period hours of labor services supplied in a match. In the limit, the number of hours $h_{t}$ is fixed. In the extensive margin model discussed in the previous section, the number of hours was normalized to 1 for convenience. Business cycle volatility is instead characterized by volatility in both hours and employment. A reasonable description of the data should then admit for the possibility of variable hours. In a model with both the intensive and the extensive margin it holds:

$$
\begin{aligned}
M C_{t} & =\frac{1}{f_{t}^{\prime} h_{t}}\left\{w_{t} h_{t}+\frac{\kappa}{q\left(\theta_{t}\right)}-(1-\rho) E_{t} \beta\left(\frac{\lambda_{t+1}}{\lambda_{t}}\right) \frac{\kappa}{q\left(\theta_{t+1}\right)}\right\} \\
& =\frac{w_{t} h_{t}}{f_{t}^{\prime} h_{t}}+\frac{1}{f_{t}^{\prime} h_{t}}\left\{\frac{\kappa}{q\left(\theta_{t}\right)}-(1-\rho) E_{t}\left[\frac{1}{r_{t}} \frac{\kappa}{q\left(\theta_{t+1}\right)}\right]\right\}
\end{aligned}
$$

where $r_{t}^{-1}=E_{t} \beta\left(\frac{\lambda_{t+1}}{\lambda_{t}}\right)$ up to a first order approximation, $f_{t}=Z_{t} N_{t} h_{t}$ and $f_{t}^{\prime}=$ $\partial Z_{t} N_{t} h_{t} / \partial\left(N_{t} h_{t}\right)$. Comparing (33) and (37) note that the first term in brackets corresponds in the data to the wage bill in either model. The ratio multiplying the term in brackets is the inverse of labor productivity per-employee in both models, since for $f_{t}=Z_{t} N_{t}$ we have $f_{t}^{\prime}=Z_{t}=Y_{t} / N_{t}$ and for $f_{t}=Z_{t} N_{t} h_{t}$ we have $f_{t}^{\prime} h_{t}=Y_{t} / N_{t}$. Therefore the two models imply the same empirical relationship in the data ${ }^{6}$. The first term in (38) can be written as $w_{t} h_{t} N_{t} / Y_{t}$. This is the labor share measure (or unit labor cost) entering as the driving variable in the traditional New Keynesian inflation equation. We label this term $M C_{t}^{N K}$, so that we can write:

$$
M C_{t}=M C_{t}^{N K}+\frac{1}{L P_{t}}\left\{\frac{\kappa}{q\left(\theta_{t}\right)}-(1-\rho) E_{t}\left[\frac{1}{r_{t}} \frac{\kappa}{q\left(\theta_{t+1}\right)}\right]\right\}
$$

where $L P_{t}$ is labor productivity per employee. When the cost of search goes to zero, the marginal cost measure converges to the standard New Keynesian definition of real marginal cost.

The equilibrium condition (35) for $\tau_{t}$ is instead not invariant to the addition of an intensive margin. When the disutility for hours worked is added to the household's preference specification, the net value of a match for the worker also depends on the marginal rate of substitution between leisure and consumption $M R S_{t}$. Nash wage bargaining then implies:

$$
\tau_{t} \equiv \frac{V\left(h_{t}\right)}{U_{C_{t}}^{\prime}}+w^{u}+\left(\frac{1}{1-b}\right)\left\{\frac{\kappa}{q\left(\theta_{t}\right)}-\beta(1-\rho) E_{t}\left(\frac{\lambda_{t+1}}{\lambda_{t}}\right)\left[1-b \theta_{t+1} q\left(\theta_{t+1}\right)\right] \frac{\kappa}{q\left(\theta_{t+1}\right)}\right\}
$$

\footnotetext{
${ }^{6}$ If the production function includes capital and this input can be reallocated across firms, the term multypling the curly brackets would be $1 / \alpha Z_{t}\left(N_{t} h_{t}\right)^{\alpha-1} K^{1-\alpha}=1 /\left[\frac{\alpha Y_{t}}{N_{t}}\right]$. Up to a first order approximation, the definition of $M C_{t}$ would be identical to the one in a model without capital.
} 
where $V\left(h_{t}\right)$ is the utility cost of hours worked per employee, and $\frac{V\left(h_{t}\right)}{U_{C_{t}}^{\prime}}=M R S_{t}$, which is unobservable.

In a model with the extensive and intensive margin, profit maximization implies $1 / \mu_{t}=M C_{t}$ is also equal in equilibrium to the ratio of the marginal rate of substitution between hours and consumption for the worker, and the marginal product of labor of an additional hour $M P L_{t}$. While this implies that, as in the New Keynesian model, the driving variable for inflation can be written in terms of the ratio between $M P L_{t}$ and $M R S_{t}$, this ratio does not correspond to the real wage per unit of output, and cannot be measured using unit labor cost data. Profit maximization only requires that at optimum the cost of producing the marginal unit of output by adding an extra hour of work must be equal to the hourly cost in units of consumptions of producing the marginal unit of output by adding an extra worker: $M C_{t}=\tau_{t} / h_{t}$.

\subsection{Estimation Equation}

Log-linearizing around the steady state equation (39) gives:

$$
\begin{aligned}
\widehat{m c}_{t}= & \frac{M C_{s s}^{N K}}{M C_{s s}} \widehat{m c}_{t}^{N K}-\left\{\frac{1}{M C_{s s}} \frac{1}{L P_{s s}}[1-(1-\rho) \beta] \frac{1}{q_{s s}} \kappa\right\} \widehat{l p}_{t} \\
& -\left\{\frac{1}{M C_{s s}} \frac{1}{L P_{s s}} \frac{1}{q_{s s}} \kappa\right\} \widehat{q}_{t}+\left\{\frac{1}{M C_{s s}} \frac{1}{L P_{s s}}(1-\rho) \beta \frac{1}{q_{s s}} \kappa\right\} \widehat{r}_{t} \\
& +\left\{\frac{1}{M C_{s s}} \frac{1}{L P_{s s}}(1-\rho) \beta \frac{1}{q_{s s}} \kappa\right\} E_{t} \widehat{q}_{t+1}
\end{aligned}
$$

To take this equation to the data, two modification to the model are necessary to allow for long-term productivity growth. First, as the marginal product of labor increases over time, the search cost in terms of output produced shrinks to zero. Second, output per worker increases steadily over time. As a consequence, conditional on our definition of the production function the variable $L P_{t}$ has no steady state.

We assume a production function:

$$
\begin{aligned}
Y_{t} & =A_{t} Z_{t} N_{t} h_{t} \\
\ln A_{t} & =\ln A_{t-1}+\mu_{a}+\varepsilon_{a_{t}} \\
\ln Z_{t} & =\rho_{z} \ln Z_{t-1}+\varepsilon_{z_{t}}
\end{aligned}
$$

where $\varepsilon_{z}, \varepsilon_{a}$ are two white noise processes, $\mu_{a}$ is the average growth rate of productivity, and the steady state value of the stationary component of productivity is $Z_{s s}=1$. We then assume that the cost of posting a vacancy grows at the same rate as $A_{t}$ so that it is a constant share of output in steady state. The wholesale firm first order condition is then:

$$
V_{t}^{J}=\frac{\kappa A_{t}}{q\left(\theta_{t}\right)}=\frac{A_{t} f_{t}^{\prime} h_{t}}{\mu_{t}}-w_{t} h_{t}+(1-\rho) E_{t} \beta\left(\frac{\lambda_{t+1}}{\lambda_{t}}\right) \frac{\kappa A_{t+1}}{q\left(\theta_{t+1}\right)},
$$


where $f_{t}^{\prime}=Z_{t}$ indicates the same quantity as in eq. (39). The first order condition can be written as:

$$
\begin{aligned}
M C_{t} & =M C_{t}^{N K}+\frac{1}{A_{t} f_{t}^{\prime} h_{t}}\left\{\frac{\kappa A_{t}}{q\left(\theta_{t}\right)}-(1-\rho) E_{t}\left[\frac{1}{r_{t}} \frac{\kappa A_{t+1}}{q\left(\theta_{t+1}\right)}\right]\right\} \\
& =M C_{t}^{N K}+\frac{1}{L P_{t}}\left\{\frac{\kappa}{q\left(\theta_{t}\right)}-(1-\rho) E_{t}\left[\frac{1}{r_{t}} \frac{A_{t+1}}{A_{t}} \frac{\kappa}{q\left(\theta_{t+1}\right)}\right]\right\},
\end{aligned}
$$

where $L P_{t}=Y_{t} /\left(A_{t} N_{t}\right)$. Loglinearizing eq. (41) and using the inflation equation we obtain the estimation equation:

$$
\begin{aligned}
\pi_{t}= & \beta E_{t} \pi_{t+1}+\delta \frac{M C_{s s}^{N K}}{M C_{s s}} \widehat{m c}_{t}^{N K} \\
& -\delta\left\{\frac{1}{M C_{s s}} \frac{1}{L P_{s s}}\left[1-(1-\rho) \beta e^{\mu_{a}}\right] \frac{1}{q_{s s}} \kappa\right\} \widehat{l p}_{t} \\
& -\delta\left\{\frac{1}{M C_{s s}} \frac{1}{L P_{s s}} \frac{1}{q_{s s}} \kappa\right\} \widehat{q}_{t} \\
& +\delta\left\{\frac{1}{M C_{s s}} \frac{1}{L P_{s s}}(1-\rho) \beta \frac{1}{q_{s s}} \kappa e^{\mu_{a}}\right\} \widehat{r}_{t} \\
& +\delta\left\{\frac{1}{M C_{s s}} \frac{1}{L P_{s s}}(1-\rho) \beta \frac{1}{q_{s s}} \kappa e^{\mu_{a}}\right\} E_{t} \widehat{q}_{t+1} \\
+ & \delta\left\{\frac{1}{M C_{s s}} \frac{1}{L P_{s s}}(1-\rho) \beta \frac{1}{q_{s s}} \kappa e^{\mu_{a}}\right\} \varepsilon_{a_{t}}
\end{aligned}
$$

\subsection{Reduced Form Estimates}

We estimate the reduced form coefficients of the inflation equation:

$$
\begin{aligned}
\pi_{t} & =\beta E_{t} \pi_{t+1}+\beta_{1} \widehat{m c}_{t}^{N K}+\beta_{2} \widehat{l p}_{t}+\beta_{3} \widehat{q}_{t}+\beta_{4} \widehat{r}_{t}+\beta_{5} E_{t} \widehat{q}_{t+1}+\gamma \varepsilon_{a_{t}} \\
& =\beta \pi_{t+1}+\beta_{1} \widehat{m c}_{t}^{N K}+\beta_{2} \widehat{l p}_{t}+\beta_{3} \widehat{q}_{t}+\beta_{4} \widehat{r}_{t}+\beta_{5} \widehat{q}_{t+1}+\varepsilon_{t}
\end{aligned}
$$

where $\varepsilon_{t}$ is the linear combination of two white noise random variables: $\gamma \varepsilon_{a_{t}}$ and the forecast errors for the variables $q_{t+1}$ and $\pi_{t+1}$. Reduced form estimates are a useful first step to verify that the regressors - consistent with the DSGE model - enter significantly into the estimated equation without imposing any theoretical restriction.

The equation is estimated with a two-stage GMM estimator using quarterly US data over the samples 1960:1 - 2004:1 and 1960:1 - 2007:1. The econometric specification nests the traditional New Keynesian definition of marginal cost and allows a test of the hypothesis that labor market search frictions significantly affect the dynamics of inflation. The estimation procedure follows Galí and Gertler (1999) and Galí, Gertler, López-Salido (2001).

Let $\mathbf{z}_{t}$ be a vector of variables within firms' information set $\Omega_{t}$ that are orthogonal to $\varepsilon_{t}$. Then (43) implies the orthogonality condition 


$$
\mathrm{E}_{t}\left[\left(\pi_{t}-\beta \pi_{t+1}-\beta_{1} \widehat{m c}_{t}^{N K}-\beta_{2} \widehat{l p}_{t}-\beta_{3} \widehat{q}_{t}-\beta_{4} \widehat{r}_{t}-\beta_{5} \widehat{q}_{t+1}\right) \mathbf{z}_{t}\right]=0 .
$$

For $\beta_{2}=\beta_{3}=\beta_{4}=\beta_{5}=0,(44)$ gives the standard Calvo pricing model.

Data The data for inflation $\pi_{t}$, unit labor cost $\widehat{m c}_{t}^{N K}$ and per-employee productivity $\widehat{l p}_{t}$ are obtained from the BLS statistics for the US nonfarm business sector (NFB). The estimation requires a time series for the probability of filling a posted vacancy $q_{t}$. We use two alternative measures. Shimer (2005a) builds a series for the job-finding probability $p_{t}$ using unemployment and short-term unemployment data from the BLS ${ }^{7}$. Given the matching function $M_{t}=\eta v_{t}^{\xi} s_{t}^{1-\xi}$ the probability of filling a vacancy is given by

$$
q_{t}=\frac{p_{t}}{\theta_{t}}
$$

Using the series for labor market tightness $\theta_{t}$ in Shimer (2005a) we obtain a time series for $q_{t}$ up to the first quarter of 2004. Following Shimer, the log-deviation $\widehat{q}_{t}$ is obtained using a slow-moving long-term trend provided by the Hodrick-Prescott filtered series for the variable, with smoothing parameter $\lambda=10^{5}$.

We build an alternative measure for $q_{t}$ splicing the JOLTS vacancy data starting in 2000 with the synthetic vacancy rate series estimated by Valletta (2005) starting in $1960^{8}$. The vacancy series $v_{t}$ is obtained from BLS nonfarm business data for payroll employment $P E_{t}$ using the equation:

$$
v_{t}=\frac{v_{t}^{\text {rate }}}{1-v_{t}^{\text {rate }}} P E_{t}
$$

Using the BLS NFB data for total unemployment we obtain a series for $\theta_{t}$ :

$$
\theta_{t}=\frac{v_{t}}{s_{t}}
$$

Finally, $q_{t}^{s y n}=\eta \theta_{t}^{\xi-1}$ and

$$
\widehat{q}_{t}^{s y n}=(\xi-1) \widehat{\theta}_{t}
$$

Figure 4 plots the two series for $\widehat{q}_{t}$, where we used the estimate $\xi=0.72$ reported in Shimer $(2005 \mathrm{a})^{9}$ to build $\widehat{q}_{t}^{\text {syn }}$. The difference between the two series is minimal. A third

\footnotetext{
${ }^{7}$ Shimer (2005b) builds a series for the job-finding probability $p_{t}$ using monthly data from the BLS under the assumption that job offers are available according to a Poisson distribution, and shows that accounting for entry and exit from the labor force does not alter the series significantly. The results are robust to using this alternative $p_{t}$ series.

${ }^{8}$ Valletta (2005) corrects the help wanted index series for secular movements unrelated to the labor market using the estimated coefficients from a regression of JOLTS data over help-wanted index data for the overlapping period after 2000 .

${ }^{9}$ The parameterization of $\xi$ is irrelevant for the reduced form estimates, but helps identification in the structural estimates.
} 
way to build $q_{t}$ is to use the definition:

$$
q_{t}=\frac{M_{t}}{v_{t}}
$$

The model though defines the number of employed workers as $N_{t}=L F_{t}-s_{t}+M_{t}$ where $L F_{t}$ is the labor force (normalized to 1 ). Since this equation implies the labor force is given by the sum of unemployed workers at the beginning of the period, employed workers at the end of the period, and new matches, it does not correspond to the BLS definition of labor force, which is given by $L F_{t}=N_{t}+s_{t}$, and cannot be used to compute the number of new matches $M_{t}$.

Our instrument vector $\mathbf{z}_{t}$ includes four lags of NFB unit labor costs, the price inflation measure, NFB per-employee labor productivity, vacancy-filling probability, NFB hourly compensation inflation, HP-filtered NFB output, federal funds rate, industrial commodities price index, unemployment rate, and the three months-ten year US government bond spread.

Estimates Table 1 reports the estimates using an instrumental variables two-stage GMM estimator and the specification of the orthogonality condition as in equation (44). All standard errors are Newey-West corrected to take into account residual serial correlation $^{10}$. We examine three alternative measures of inflation. In all cases, all coefficients are significantly different from zero with a high confidence level. The only exception is the significance of the labor productivity coefficient in the case inflation is measured by the consumer price index. The difference between the values of the maximized criterion function for the restricted and unrestricted model can be used to perform the equivalent of a likelihood ratio test for the null hypothesis that $\beta_{2}=\beta_{3}=\beta_{4}=\beta_{5}=0$. This test, known in the literature as a D-test (see Matyas, 1999) shows that the traditional New Keynesian Phillips Curve is in all cases rejected in favor of the search-friction specification. The signs of the estimated parameter correspond to the theory prediction in all cases but for the unit labor cost measure. The restricted regression shows that, consistent with the theory, unit labor costs are estimated to enter with a positive coefficient in the inflation equation when the search friction is not included in the specification.

Using the synthetic vacancy data, the unrestricted regression estimates are consistent with the earlier results. Surprisingly, in the restricted regression the coefficient for unit labor costs is not significant. The cross-correlation between inflation and unit labor cost (figure 5) shows why the very fact of extending the sample up to 2007 causes the equation to break down. Inflation is positively correlated with contemporaneous and future values of unit labor cost up to 1995 - as predicted by the theory - while the cross-correlation is reversed in the sample 1995 to 2007. As the sample for the synthetic data includes an

\footnotetext{
${ }^{10}$ The Newey-West correction implies a larger acceptance region for the parameter significance, and may result in high p-values for the parameter estimates.
} 
additional three years of data in the second part of the sample, the sign for the unit labor cost variable is estimated with less precision.

Since inflation in the standard New Keynesian model is equal to the expected discounted sum of future real marginal costs, the finding of a negative correlation between inflation and future unit labor cost suggests that either the standard equation is misspecified, or unit labor costs are not an accurate measure of marginal costs. The search friction Calvo model built in the preceding sections implies that the cost of forming a match should enter in firms' marginal cost. We cannot directly observe the marginal cost variable, since it is a linear combination of unit labor costs and current and expected hiring costs. Using the estimates for the unrestricted inflation equation in Table 1 it is possible to build an estimate of the true marginal cost. Figure 6 shows that inflation is positively correlated with the leads of the marginal cost, consistently with the theory, and that this relationship is stable across subsamples.

Yet the estimates in Table 1 present us with a puzzle: they imply that an increase in current unit labor cost leads to a decrease in inflation. Mis-measurement or misspecification can lead to this result. One possibility is that vacancies, used to build the labor market tightness variable, are measured incorrectly. Job vacancies include both positions filled with unemployed workers $\left(v^{u}\right)$, and positions filled with job to job workers' transitions $\left(v^{e}\right)$. But our model is built to explain only movements in $v^{u}$, which are unobservable. The hypothesis that $v$ is highly correlated with the measure of vacancies implied by the model, and therefore the measured $v$ is a good proxy for $v^{u}$, has been shown to be partially inconsistent with available estimates of the matching function (Yashiv, 2005). The possibility of mis-specification is discussed in the following.

A Test of the Cost Channel Eq. (42) provides an additional testable implication of the search friction Calvo model. The coefficients on $\widehat{r}_{t}, \widehat{q}_{t+1}$ are identical. This restriction is consistently rejected by the data across all specification.

The estimates show that the coefficient $\beta_{4}$ on $\widehat{r}_{t}$ is an order of magnitude larger than the coefficient $\beta_{5}$ on $\widehat{q}_{t+1}$. Since both coefficients are estimated with low variance, rejection of the restriction is not surprising. The intuition for this result sheds light on the working of the model. The restriction $\beta_{4}=\beta_{5}$ obtains since in eq. (41) the future expected cost of posting a vacancy is discounted at the real rate of interest. Since the real rate of interest and the probability of filling a vacancy enter with the same coefficient in the definition of $M C_{t}$, they should have a variance of the same order of magnitude. On the contrary, in the data $q_{t}$ has a variance which is an order of magnitude larger than $r_{t}$, as shown in figure 4 . Therefore the estimate results in $\beta_{5}<<\beta_{4}$.

A different model may have a prediction consistent with the difference in variance between $r_{t}$ and $q_{t}$. It is not straightforward to build a plausible model with this implication. It would need to have a term $q_{t+1}^{x}$ with $x<1$, or, the cost of posting a vacancy should 
be concave in the probability of a position being filled.

The existence of a cost channel can easily justify an estimate for $\beta_{5}$ much smaller than $\beta_{4}$. If firms have to pay in advance the factors of production, the term $M C_{t}^{N K}$ in eq. (41) will be multiplied by the cost of borrowing funds $\left(1+i_{t}\right)$. This provides the necessary degree of freedom in eq. (42), that can now be rewritten as:

$$
\begin{aligned}
\pi_{t}= & \left\{[\beta]+\left[-\delta \frac{1}{M C_{s s}} \frac{1}{L P_{s s}}(1-\rho) \beta \frac{1}{q_{s s}} \kappa e^{\mu_{a}}\right]\right\} E_{t} \pi_{t+1} \\
& +\delta \frac{M C_{s s}^{N K}}{M C_{s s}} \widehat{m c}_{t}^{N K} \\
& -\delta\left\{\frac{1}{M C_{s s}} \frac{1}{L P_{s s}}[1-(1-\rho) \beta] \frac{1}{q_{s s}} \kappa\right\} \widehat{l p}_{t} \\
& -\delta\left\{\frac{1}{M C_{s s}} \frac{1}{L P_{s s}} \frac{1}{q_{s s}} \kappa\right\} \widehat{q}_{t} \\
& +\delta\left\{\left[\alpha^{\cos t}\right]+\left[\frac{1}{M C_{s s}} \frac{1}{L P_{s s}}(1-\rho) \beta \frac{1}{q_{s s}} \kappa e^{\mu_{a}}\right]\right\} \widehat{i}_{t} \\
& +\delta\left\{\frac{1}{M C_{s s}} \frac{1}{L P_{s s}}(1-\rho) \beta \frac{1}{q_{s s}} \kappa e^{\mu_{a}}\right\} E_{t} \widehat{q}_{t+1} \\
+ & \delta\left\{\frac{1}{M C_{s s}} \frac{1}{L P_{s s}}(1-\rho) \beta \frac{1}{q_{s s}} \kappa e^{\mu_{a}}\right\} \varepsilon_{a_{t}}
\end{aligned}
$$

In this specification, the coefficient on $\widehat{i}_{t}$ and $E_{t} \widehat{q}_{t+1}$ are not restricted to be equal, while $\alpha^{\cos t}$ is the share of factor payment that firms have to pay in advance (see Ravenna and Walsh, 2006). Table 2 provides estimates of the cost-channel specification. As expected, the only estimate that changes is the one for $\beta$, now estimated to be smaller, as predicted by the theory. The traditional New Keynesian Phillips Curve is rejected by the data in favor of the search-friction specification, even after the inclusion of the cost channel.

Lagged Inflation Many authors have concluded that at the very least a small but significant backward looking inflation component is consistent with estimates of the New Keynesian Phillips Curve, although the inclusion of a lagged inflation term raises a number of econometric issues. Since labor market variables are typically lagging indicators of the business cycle, we would like to test the hypothesis that $q_{t}$ is not significant simply because it proxies for lagged inflation. Table 3 shows the result of the reduced form GMM estimates of the equation:

$$
\pi_{t}=\beta_{0} E_{t} \pi_{t+1}+\beta_{1} \widehat{m c}_{t}^{N K}+\beta_{2} \widehat{l p}_{t}+\beta_{3} \widehat{q}_{t}+\beta_{4} \widehat{i}_{t}+\beta_{5} E_{t} \widehat{q}_{t+1}+\beta_{6} \pi_{t-1}+\gamma \varepsilon_{a_{t}}
$$

The specification includes the regressor $i_{t}$ rather than $r_{t}$ to allow explicitly for the existence of a cost channel. The term $\pi_{t-1}$ enters significantly in the search-friction New Keynesian Phillips Curve, but all the other coefficients remain significant. It also enters 
significantly in the traditional New Keynesian Phillips Curve. We conclude that the labor market variables play a role in explaining inflation dynamics that goes beyond proxing for lagged inflation.

\subsection{Structural Estimates}

Using a non-linear GMM estimator, and restrictions obtained from the theory, it is possible to estimate the structural parameters in eq. (42). To illustrate the identification issues in the estimation it is convenient to rewrite the inflation equation as:

$$
\begin{aligned}
\omega \pi_{t}= & \omega \beta E_{t} \pi_{t+1} \\
& +(1-\omega)(1-\beta \omega) \frac{M C_{s s}^{N K}}{M C_{s s}} \widehat{m c}_{t}^{N K} \\
& -(1-\omega)(1-\beta \omega)\left\{\frac{1}{M C_{s s}} \frac{1}{L P_{s s}} \frac{1}{q_{s s}} \kappa\right\}\left[\widehat{l p}_{t}+\widehat{q}_{t}\right] \\
& +(1-\omega)(1-\beta \omega)\left\{\frac{1}{M C_{s s}} \frac{1}{L P_{s s}}(1-\rho) \beta \frac{1}{q_{s s}} \kappa e^{\mu_{a}}\right\}\left[\widehat{l p}_{t}+\left(\widehat{r}_{t}+E_{t} \widehat{q}_{t+1}\right)\right] \\
& +\delta\left\{\frac{1}{M C_{s s}} \frac{1}{L P_{s s}}(1-\rho) \beta \frac{1}{q_{s s}} \kappa e^{\mu_{a}}\right\} \varepsilon_{a_{t}}
\end{aligned}
$$

Identification is possible for at most four parameters. Using the model steady state restrictions it is possible to estimate the discount factor $\beta$, the probability of price adjustment $(1-\omega)$, the separation rate $\rho$ and the cost of posting a vacancy $\kappa$.

To this end, we make the following assumptions. The steady state value of the marginal cost $M C_{s s}$ is equal to the inverse of the markup $\mu=\frac{\vartheta}{\vartheta-1}$. Consistent with the New Keynesian literature, we assume $\mu=1.2$. The average growth rate of the permanent technology shock $A_{t}$ is estimated from real GDP data for the NFB sector using the model's restriction:

$$
E\left[\ln \left(\frac{A_{t}}{A_{t-1}}\right)\right]=E\left[\ln \left(\frac{Y_{t}}{Y_{t-1}}\right)\right]=\mu_{a}
$$

Over the 1960:1-2007:1 sample the estimate for $\mu_{a}$ is 0.8938 . The steady state value of the vacancy-filling probability $q_{s s}$ is parameterized to be approximately equal to 0.7 , consistently with available estimates on US data (Blanchard and Gali, 2006). The coefficient $L P_{s s}$ is equal to $h_{s s} Z_{s s}$. We normalize this value to $1^{11}$. Finally, the coefficient $M C_{s s}^{N K}$ needs to be parameterized. Since there exist search frictions this coefficient is not equal to $\mu^{-1}$ as in the standard New Keynesian Phillips Curve. The budget constraint

\footnotetext{
${ }^{11}$ In an economy with capital $L P_{s s}=Z_{s s}\left(\frac{K}{N h}\right)_{s s}^{\alpha_{k}}$ and it is still possible to choose the units of $Z$ such that $L P_{s s}=1$.
} 
and the wholesale sector zero-profit condition imply:

$$
\begin{aligned}
w_{t} N_{t} & =\frac{P_{t}^{w}}{P_{t}} Y_{t}^{w}-\kappa v_{t} \\
& \rightarrow M C_{s s}-\frac{\kappa v_{t}}{Y_{t}^{w}}=\frac{w_{t} N_{t} h_{t}}{Y_{t}^{w}}=M C_{s s}^{N K}
\end{aligned}
$$

If the cost of search $\kappa$ is small as a share of output - as in most parameterization of the search labor market framework - it approximately holds:

$$
M C_{s s}=\frac{1}{\mu} \simeq M C_{s s}^{N K}
$$

and the ratio $\frac{M C_{s s}^{N K}}{M C_{s s}}$ is approximately equal to unity. Note that in a model with capital, this ratio would be a function of the steady state labor share and the steady state markup. Using as a measure of labor share the share of employees' total compensation on national income, the sample 1960:1-2007:1 provides an estimate for $M C_{s s}^{N K}$ equal to $0.71^{12}$. The estimation uses $M C_{s s}^{N K}=\mu^{-1}$. Results obtained using the average labor's share are not qualitatively different.

Table 4 reports the structural parameters estimate. The estimated value for $\omega$ is 0.86 . This value implies an average price duration of about 7 quarters. Microeconomic evidence for the US supports a shorter price duration. Aggregate estimates of New Keynesian Phillips Curve are instead often in this range, and an aggregation bias has been proposed as an explanation for the discrepancy. Gali and Gertler (1999) report estimated values for $\omega$ between 0.82 and 0.91 . The estimated value for $\beta$ is 0.96 , consistent with the theory and the literature. The estimation predicts a separation rate of 0.35 , which is high compared to the evidence from micro data. All parameter estimates are significant, and have sign consistent with the theory.

The estimate for $\kappa$ has an interesting interpretation. Since $\frac{A_{t} \kappa v_{t}}{Y_{t}}$ is the total perperiod cost of search in the economy as a share of output, we can compute the cost of search as :

$$
\text { Cost }=\frac{\frac{\kappa v_{t}^{\text {rate }}}{n_{t}^{\text {tate }}}}{\frac{Y_{t}}{A_{t}}}
$$

where $n_{t}^{\text {rate }}, v_{t}^{\text {rate }}$ are respectively the employment and vacancy rate (consistently with the model, where the labor force is normalized to 1) and $Y_{t} / A_{t}$ is the exponential of the Hodrick-Prescott filtered output. Figure 7 plots the time series for Cost over the last 40 years. As it turns out, most of its variation derives from the volatility of the vacancy rate, which is by far more volatile than output.

\footnotetext{
${ }^{12}$ In a model where capital cannot be instantaneously reallocated across firms, an additional correction to the inflation equation is needed to allow for the fact that price-setting firms' marginal cost will be different from the average cost. Assuming $Y_{t}=Z_{t}\left(N_{t} h_{t}\right)^{\alpha} K_{t}^{1-\alpha}$ the marginal cost is $M C_{t}=\alpha[1+(1-$ $\alpha)(\varepsilon-1)]^{-1} A C_{t}$ where the average cost $A C$ is defined by equation (38). See Sbordone (2002).
} 


\subsection{Alternative Specifications}

The unrestricted reduced form estimates presented us with the puzzling implication of a rise in unit labor costs having a negative impact on inflation. Mis-measurement in vacancies could explain this result. At the same time, the estimated model is highly stylized. This section explores some alternative specifications that can potentially drive the model closer to the data.

First, consider a model with a time-varying separation rate $\rho_{t}$. The evidence pointing to the stability of $\rho_{t}$ in US data is strong only for the short period covered by JOLTS data. Estimates for previous periods have shown a higher volatility. An (exogenously) time varying separation rate would add to the estimation equation (42) the term

$$
\delta\left\{\frac{1}{M C_{s s}} \frac{1}{L P_{s s}} \rho \beta \frac{1}{q_{s s}} \kappa e^{\mu_{a}}\right\} E_{t} \widehat{\rho}_{t+1}
$$

where $\rho$ is now the steady state value of $\rho_{t}{ }^{13}$.

Second, the cost of vacancy posting need not be constant. A large part of the literature assumes convex costs, though Rotemberg (2005) proposes a model with concave costs where firms face economies of scale when searching for many positions at one time. Assume a cost function (Yashiv, 2005):

$$
\kappa_{t}=\frac{\kappa}{1-\gamma}\left[\phi \frac{v_{t}}{N_{t}}+(1-\phi) \frac{q_{t} v_{t}}{N_{t}}\right]^{\gamma+1} Y_{t}
$$

Vacancy posting costs are proportional to output, and depend both on the number of posted vacancies (and on labor market tightness since $\theta_{t}=v_{t} / N_{t}$ ) and on the number of hires $M_{t}=q_{t} v_{t}$. In the extensive margin model, $Y_{t}=A_{t} Z_{t} N_{t}$ and for $\gamma=0, \phi=1$ eq. (45) gives $\kappa_{t}=\kappa v_{t} A_{t} Z_{t}$, a formulation identical to the one assumed in the model save for the proportionality to stationary technology shocks. Formulations with $\gamma>0$ give a convex cost function. This model implies that eq. (42) should be augmented with three terms in $\widehat{\theta}_{t}, E_{t} \widehat{\theta}_{t+1}, E_{t} \widehat{L P}_{t+1}$.

Third, the existence of 'overhead labor' that must be hired regardless of output implies a production function of the form $Y=f\left(Z_{t}, A_{t},\left(N_{t}-N\right) h_{t}\right)$. Assuming a technology linear in labor, we obtain

$$
Y_{t}=A_{t} Z_{t}\left(N_{t}-N\right)
$$

Since now the marginal product of labor is different from the average product, it holds that $\frac{\partial Y_{t}}{\partial N_{t}}=\frac{Y_{t}}{N_{t}}\left(\frac{N_{t}}{N_{t}-N}\right)$ and $\frac{w_{t} h_{t}}{Z_{t} h_{t}}=U L C_{t}\left(1-\frac{N}{N_{t}}\right)$ where $U L C$ is unit labor cost. The production function (46) requires that a term in $\widehat{N}_{t}$ be added to the estimation equation $(42) \cdot{ }^{14}$

\footnotetext{
${ }^{13}$ The equation must include the expectation, rather than the current value, of $\rho_{t}$ since separation occur after the match has been productive in $t$, and separated workers enter into the $t+1$ pool of searchers.

${ }^{14}$ Note that neither the existence of a 'setup cost' per employee, as in Basu and Kimball (1994), nor
} 
Fourth, the cost of adjusting the labor input on the intensive margin may be non-zero. If this cost is convex in hours and is proportional to the number of employees, it will affect the first order condition for vacancy posting, given the firm revenues are decreased by the cost $g\left(h_{t}, h_{t-1}\right) N_{t}$. It is easy to show that under very general conditions for the cost function $g($.$) the estimation equation would be augmented by two terms in \widehat{h}_{t}, \widehat{h}_{t-1}$.

When the four alternative specifications are estimated with the GMM estimator, in all cases the unit labor cost variable still enters significantly, and with a negative coefficient, in the inflation equation - even in cases where the added variables turn out to be significant.

\section{Conclusions}

The relationship between inflation and economic activity has always been at the heart of macroeconomic models used for policymaking, since it summarizes the constraint faced by the central bank when setting monetary policy. While this basic relationship has taken for decades the shape of a Phillips curve, relating unemployment and inflation, modern macroeconomic theory based on dynamic stochastic general equilibrium models relies on Walrasian labor markets, where involuntary unemployment is ruled out by assumption. The new Keynesian paradigm assumes all variation in labor input occurs along the intensive hours margin, and the driving variable for inflation depends on workers' marginal rates of substitution between leisure and consumption.

This paper incorporates a search-friction model of the labor market into a sticky-price new Keynesian model of economic activity. A number of simplifying assumptions allow us to derive an equilibrium relationship between inflation and labor market variables specifically, unemployment - providing a microfoundation for the Phillips curve empirical relationship, investigated by a large literature over the last fifty years.

In contrast to earlier literature, we focus directly on the implications of the labor market specification for the Phillips curve and the connection between the structure of the labor market and the unemployment elasticity of inflation, and provide empirical testing of the model.

In our model the driving variable for inflation is the firm's marginal cost inclusive of the search cost to hire a worker. The Phillips curve relates the quasi-difference between inflation and expected inflation to lagged, current and future values of unemployment, to the real interest rate and to per-employee productivity. Since the real interest rate affects firm's marginal cost, the search-friction Phillips curve generates a supply-side channel through which monetary policy affects inflation. The inflation elasticity to unemployment is decreasing in the probability of a firm-worker match separating, and in the probability

labor hoarding would modify the estimation equation, since in both cases the production function is of the form $Y_{t}=f\left(Z_{t}, A_{t}, N_{t}\left(h_{t}-h\right)\right)$, implying the log-deviation of marginal labor productivity per employee $\frac{\partial Y_{t}}{\partial N_{t}}$ is unaffected. 
of a vacancy being filled, while is increasing in labor's bargaining power. Therefore the search-friction Phillips curve can explain cross-country differences in the dynamics of inflation as a consequence of alternative structural characteristics of the labor market

Our empirical strategy lets us test a version of the Phillips curve that is consistent with a very large family of models incorporating labor market search frictions, such as models with both an extensive and an intensive margin. While the most recent vintage of US data rejects the new Keynesian Phillips curve as a stable structural relationship, we show that the search-friction Phillips curve can potentially reconcile the new Keynesian model of inflation with the data. Using a GMM estimator we show that the baseline new Keynesian Phillips curve, both in its forward-looking, hybrid and cost-channel formulations, is consistently rejected in favor of our model of the Phillips curve. Structural estimates show that the total per-period cost of search in the US economy since 1960 has been of the order of $0.10 \%$ of non nonfarm business sector output.

Our model provides a straightforward test of the relevance of search frictions for macroeconomic volatility. A puzzle remains as to the fact that the theoretical restriction of a positive impact of unit labor costs on inflation is rejected by the data - even when using alternative specifications. In summary, while the search friction Calvo model we presented provides a better fit to the data than the baseline New Keynesian model, it is still too stylized to fully describe the dynamics of firms' marginal costs. Additional propagation mechanisms, such as procyclical labor effort, endogenous separations, cost of firing and job to job transitions are promising avenues to explore. 


\section{Appendix}

\subsection{Wage determination}

Consider a comparison of the outcomes from the worker in making a match versus not making one. The value of the match is the wage plus the expected value of entering the following period with a job: $V_{t}^{m}=w_{t}+\beta E_{t}\left(\lambda_{t+1} / \lambda_{t}\right) V_{t+1}^{E}$. In turn,

$$
V_{t+1}^{E}=\left[1-\rho+\rho \theta_{t+1} q\left(\theta_{t+1}\right)\right] V_{t+1}^{m}+\rho\left[1-\theta_{t+1} q\left(\theta_{t+1}\right)\right] V_{t+1}^{n},
$$

since an employed worker survives the exogenous separation process and remains in a match with probably $1-\rho$, becomes unemployed with probability $\rho$ but immediately finds another job with probability $\theta_{t+1} q\left(\theta_{t+1}\right)$, or becomes unemployed with probability $\rho$ but does not find a new match.

The value of not making a match is the value of the outside opportunity plus the expected value of entering the following period unemployed: $V_{t}^{n}=w^{u}+\beta E_{t}\left(\lambda_{t+1} \cdot \lambda_{t}\right) V_{t+1}^{u}$. The value of being unemployed is

$$
V_{t+1}^{u}=\theta_{t+1} q\left(\theta_{t+1}\right) V_{t+1}^{m}+\left[1-\theta_{t+1} q\left(\theta_{t+1}\right)\right] V_{t+1}^{n} .
$$

Combining these results,

$$
\begin{aligned}
V_{t}^{s} & \equiv V_{t}^{m}-V_{t}^{n}=\left(w_{t}-w^{u}\right)+\beta E_{t}\left(\lambda_{t+1} / \lambda_{t}\right)\left(V_{t+1}^{E}-V_{t+1}^{u}\right) \\
& =\left(w_{t}-w^{u}\right)+\beta(1-\rho) E_{t}\left(\lambda_{t+1} / \lambda_{t}\right)\left[1-\theta_{t+1} q\left(\theta_{t+1}\right)\right] V_{t+1}^{s}
\end{aligned}
$$

which is (10) of the text. 


\section{References}

[1] Alexopoulos, M., "A monetary business cycle model with unemployment," University of Toronto, January 2002.

[2] Alexopoulos, M., "Unemployment and the business cycle," Journal of Monetary Economics, 51(2), March 2004, 257-298.

[3] Andolfatto, D., "Business cycles and labor-market search," American Economic Review, 86 (1), March 1996, 112-132.

[4] Bils, M. and P. Klenow, "Some evidence on the importance of sticky prices," January 2002.

[5] Blanchard, O. J. and Jordi Galí, "Real wage rigidity and the new Keynesian model," Feb. 2006.

[6] Blanchard, O. J. and Jordi Galí, "A New Keynesian Model with Unemployment," March 2006.

[7] Blanchard, O. J. and P. Diamond, "The Beveridge curve," Brookings Papers on Economic Activity, 1989, 1-60.

[8] Chéron, A. and F. Langot, 1999, "The Phillips and Beveridge curves Revisited," Economics Letters, 1999, 69, 371-376.

[9] Christiano, L. J., M. Eichenbaum, and C. Evans, "Nominal rigidities and the dynamic effects of a shock to monetary policy," Journal of Political Economy, Feb. 2005, 113 (1), 1-45.

[10] Cole, H. and R. Rogerson, "Can the Mortensen-Pissarides matching model match the business cycle facts?" International Economic Review, 40 (4), Nov. 1999, 933-959.

[11] Cooley, T. F. and V. Quadrini, "A neoclassical model of the Phillips curve relation," Journal of Monetary Economics, 44 (2), Oct. 1999 165-193.

[12] Danthine, J. P. and A. Kurmann, "Fair wages in a new Keynesian model of the business cycle," CIRPÉE Working Paper 03-02, April 2003.

[13] Davis, S. J., J. C. Haltiwanger, and S. Schuh, Job Creation and Job Destruction, Cambridge (MA): MIT Press, 1996.

[14] Estrella, A. and J. C. Fuhrer, "Dynamic inconsistencies: counterfactual implications of a class of rational expectations models," American Economic Review, 92(4), Sept. 2002, 1013-1028.

[15] Faia, Esther, "Optimal monetary policy rules with labor market frictions, March 2006.

[16] Galí, Jordi and Mark Gertler, "Inflation dynamics: A structural econometric analysis," Journal of Monetary Economics, 44 (2), Oct. 1999, 195-222. 
[17] Goodfriend, M. and R. G. King, "The new neoclassical synthesis and the role of monetary policy," NBER Macroeconomic Annual 1997, Cambridge, MA: MIT Press, 231-283.

[18] Gordon, R., "Recent Developments in the Theory of Unemployment and Inflation", Journal of Monetary Economics 1976, 2: 185-219.

[19] Hairault, Jean-Olivier, "Labor market search and international business cycles," Review of Economic Dynamics July 2002, 5(3), 535-558.

[20] Hall, R. E., "Lost jobs," Brookings Papers on Economic Activity, 1995:1, 221- 256.

[21] - , "Job Loss, Job Findning and Unemployment in the US Economy over the Past fifty Years" in Gertler, M. and Rogoff, K, eds., NBER Macroeconomics Annual 2005, Cambridge: MIT Press.

[22] Hosios, Arthur J, "On the Efficiency of matching and Related Models of Search and Unemployment," Review of Economic Studies, 57(2), 279-298, 1990.

[23] Krause, M. U. and T. A. Lubik, "The (ir)relevance of real wage rigidity in the new Keynesian model with search frictions," Oct. 2005 (JME forthcoming?)

[24] Merz, M., "Search in the labor market and the real business cycle," Journal of Monetary Economics, 36 (2), Nov. 1995, 269-300.

[25] Mortensen, D. T., "Job search, the duration of unemployment, and the Phillips curve," American Economic Review 60(5), Dec. 1970, 847-862.

[26] Mortensen, D. T. and C. A. Pissarides, "Job creation and job destruction in the theory of unemployment," Review of Economic Studies, 61 (3), July 1994, 397-416.

[27] Petrongolo, B. and C. A. Pissarides, "Looking into the black box: A survey of the matching function," Journal of Economic Literature, 39, 2001, 390-431.

[28] Ravenna, F. and C. E. Walsh, "Optimal monetary policy with the cost channel," Journal of Monetary Economics 2006, 53, 199-216.

[29] - , "The welfare costs of monetary policy and the role of the labor market", April 2007.

[30] Rotemberg, J. and Woodford, M., "The Cyclical Behavior of Prices and Costs" , in J.B. Taylor and M. Woodford, eds., Handbook of Macroeconomics, vol. 1B, 1999.

[31] Rudd, J. and Whelan, K., "Does Labor's Share drive Inflation?", Journal of Money, Credit and Banking 2005, 27: 297-311.

[32] Sbordone, A. M., "Prices and unit labor costs: A new test of price stickiness," Journal of Monetary Economics, 49(2), March 2002, 265-292.

[33] Thomas, Carlos, "Search and matching frictions and optimal monetary policy," LSE, Nov. 2006.

[34] Trigari, A., "Equilibrium unemployment, job flows and inflation dynamics," European Central Bank, Working Paper Series No. 304, Feb. 2004. 
[35] Vestin, David, "Price-Level versus Inflation Targeting," Journal of Monetary Economics, 2006, 53, 1361-1376.

[36] Walsh, C. E., "Labor market search and monetary shocks," in Elements of Dynamic Macroeconomic Analysis, S. Altûg, J. Chadha, and C. Nolan (eds.), Cambridge: Cambridge University Press, 2003, 451-486.

[37] Walsh, C. E., "Labor market search, sticky prices, and interest rate policies," Review of Economic Dynamics, 8(4), Oct. 2005, 829-849.

[38] Woodford, M., Interest and Prices - Foundations of a Theory of Monetary Policy, Princeton: Princeton University Press, 2003. 


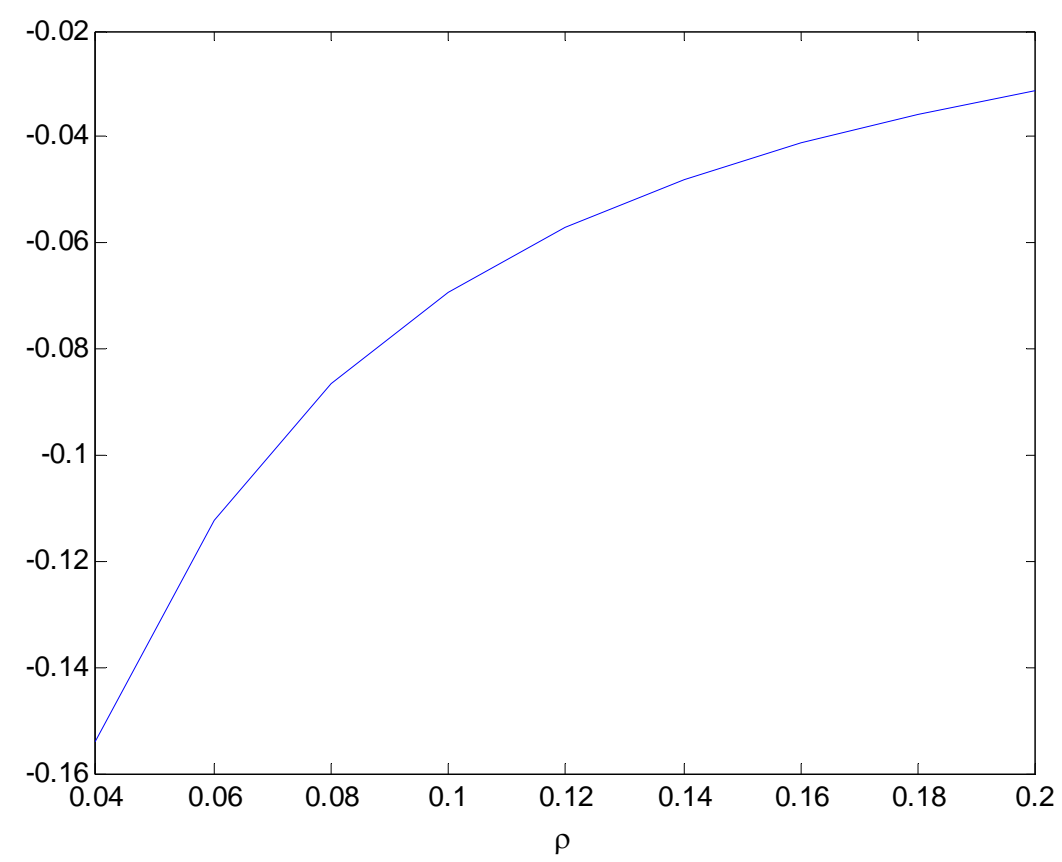

Figure 1: Effect of exogenous separation probability on the unemployment elasticity of inflation

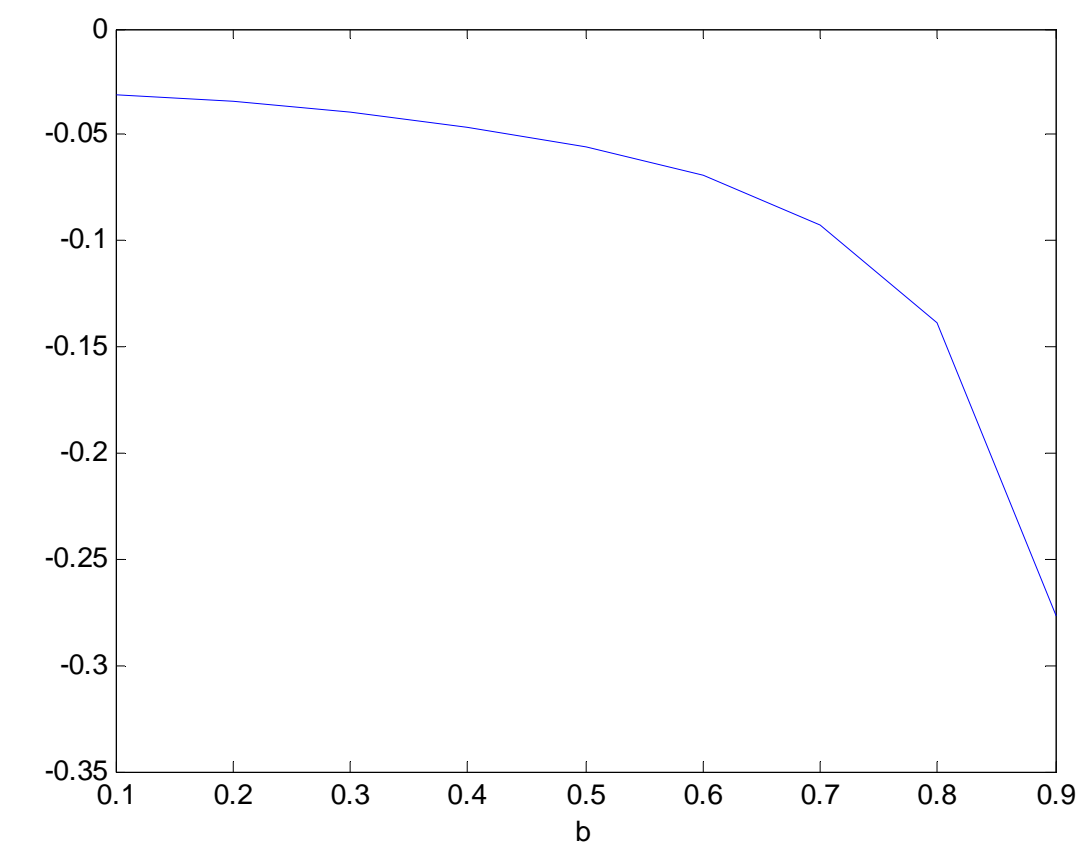

Figure 2: Effect of labor share on the unemployment elasticity of inflation 


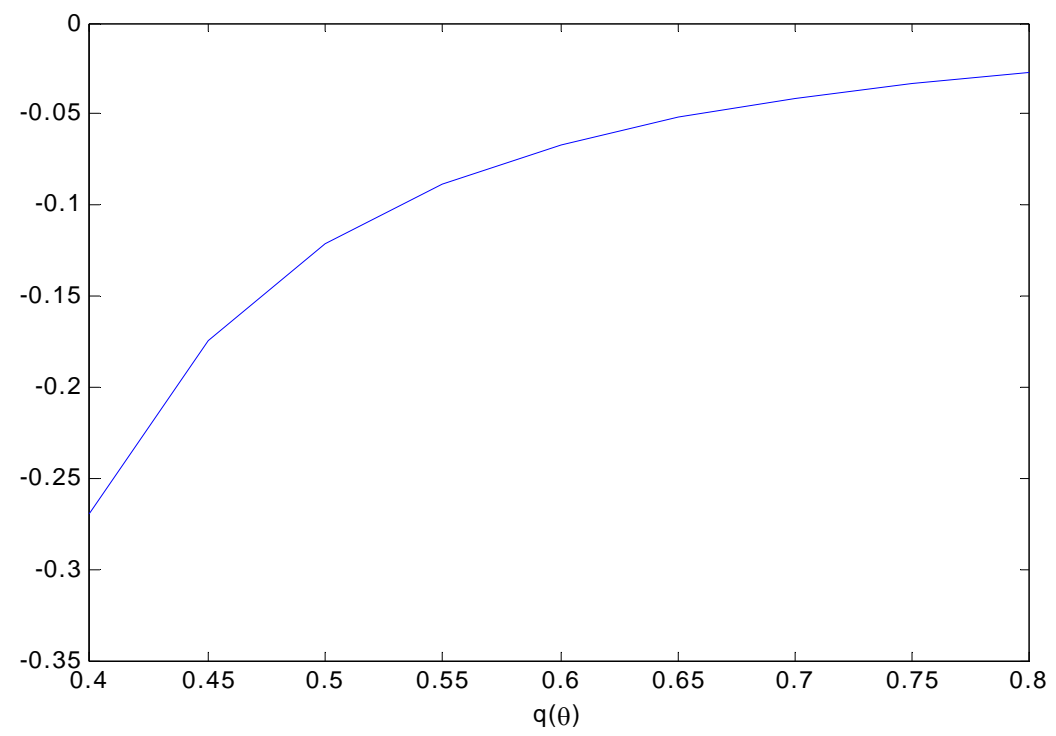

Figure 3: Effect of the job filling probability on the elasticity of inflation with respect to unemployment.

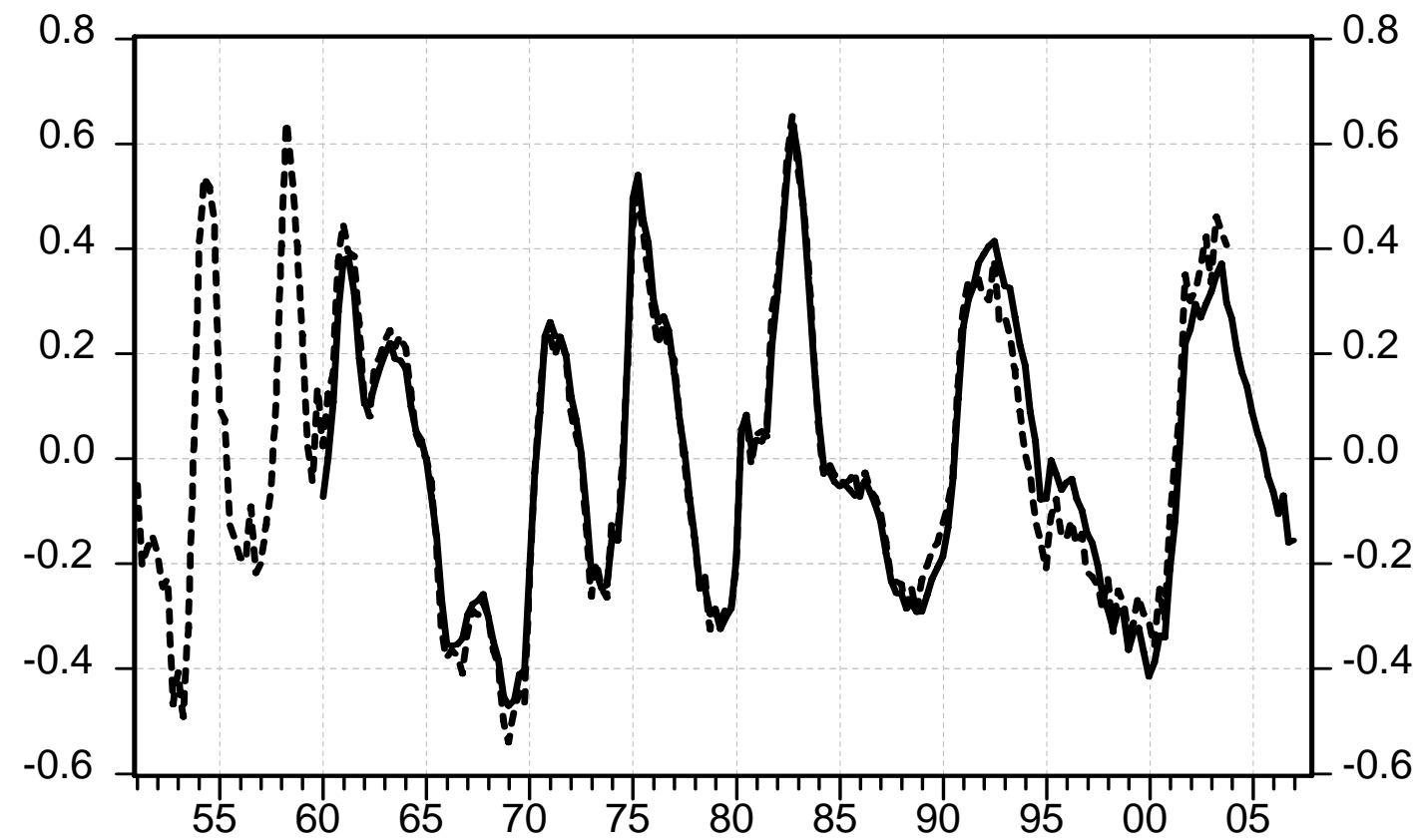

_ Synthetic vacancy-filling prob. _ _ _- Shimer (2006) vacancy-filling pr

Figure 4: Hodrick-Prescott filtered probability of filling a posted vacancy. Synthetic data computed from JOLTS and Valletta's (2005) estimate of vacancy rate over the period 1960-2000. 
Table 1: Estimates of the Phillips Curve

\begin{tabular}{|c|c|c|c|c|c|c|c|}
\hline & $\beta$ & $\beta_{1}$ & $\beta_{2}$ & $\beta_{3}$ & $\beta_{4}$ & $\beta_{5}$ & $D-t e s t$ \\
\hline \multicolumn{8}{|l|}{ NFB Pr ice Deflator } \\
\hline Restricted & $\begin{array}{c}0.957 \\
{[<0.001]}\end{array}$ & $\begin{array}{l}0.008 \\
{[0.026]}\end{array}$ & 0 & 0 & 0 & 0 & \\
\hline Unrestricted & $\begin{array}{c}0.995 \\
{[<0.001]}\end{array}$ & $\begin{array}{l}-0.016 \\
{[<0.001]}\end{array}$ & $\begin{array}{l}-0.024 \\
{[<0.001]}\end{array}$ & $\begin{array}{c}-0.003 \\
{[0.041]}\end{array}$ & $\begin{array}{c}0.092 \\
{[<0.001]}\end{array}$ & $\begin{array}{c}0.005 \\
{[<0.001]}\end{array}$ & $\begin{array}{l}230.28 \\
{[<0.001]}\end{array}$ \\
\hline \multicolumn{8}{|l|}{ GDP Price Deflator } \\
\hline Restricted & $\begin{array}{c}0.951 \\
{[<0.001]}\end{array}$ & {$\left[\begin{array}{l}0.014 \\
{[<0.001]}\end{array}\right.$} & 0 & 0 & & & \\
\hline Unrestricted & $\begin{array}{l}0.975 \\
{[0.014]}\end{array}$ & $\begin{array}{c}-0.006 \\
{[0.098]}\end{array}$ & $\begin{array}{l}-0.021 \\
{[0.003]}\end{array}$ & $\begin{array}{c}-0.003 \\
{[0.009]}\end{array}$ & $\begin{array}{l}0.067 \\
{[<0.001]}\end{array}$ & $\begin{array}{l}0.005 \\
{[<0.001]}\end{array}$ & $\begin{array}{l}210.26 \\
{[<0.001]}\end{array}$ \\
\hline \multicolumn{8}{|l|}{ CPI Inflation } \\
\hline Restricted & $\begin{array}{c}0.952 \\
{[<0.001]}\end{array}$ & $\begin{array}{l}0.017 \\
{[<0.001]}\end{array}$ & 0 & 0 & & & \\
\hline Unrestricted & $\begin{array}{c}0.988 \\
{[<0.001]}\end{array}$ & $\begin{array}{c}-0.015 \\
{[0.004]}\end{array}$ & $\begin{array}{c}-0.0008 \\
{[0.923]}\end{array}$ & $\begin{array}{l}-0.009 \\
{[<0.001]}\end{array}$ & $\begin{array}{l}0.154 \\
{[<0.001]}\end{array}$ & $\begin{array}{l}0.011 \\
{[<0.001]}\end{array}$ & $\begin{array}{l}164.70 \\
{[<0.001]}\end{array}$ \\
\hline $\begin{array}{c}\text { NFB Pr ice Deflator } \\
\text { Sample: 1960:1-2007:1 - Synthetic data } \\
\text { Restricted }\end{array}$ & {$\left[\begin{array}{c}0.972 \\
{[<0.001]}\end{array}\right.$} & $\begin{array}{c}0.0003 \\
{[0.932]}\end{array}$ & 0 & 0 & & & \\
\hline Unrestricted & $\begin{array}{l}1.002 \\
{[<0.001]}\end{array}$ & $\begin{array}{l}-0.019 \\
{[<0.001]}\end{array}$ & $\begin{array}{l}-0.027 \\
{[0.003]}\end{array}$ & $\begin{array}{c}-0.003 \\
{[0.033]}\end{array}$ & $\begin{array}{l}0.084 \\
{[<0.001]}\end{array}$ & $\begin{array}{l}0.005 \\
{[0.002]}\end{array}$ & $\begin{array}{l}161.16 \\
{[<0.001]}\end{array}$ \\
\hline
\end{tabular}

Estimates of the equation $\pi_{t}=\beta E_{t} \pi_{t+1}+\beta_{1} \widehat{m c}_{t}^{N K}+\beta_{2} \widehat{l p}_{t}+\beta_{3} \widehat{q}_{t}+\beta_{4} \widehat{r}_{t}+$ $\beta_{5} E_{t} \widehat{q}_{t+1}+\gamma \varepsilon_{a_{t}}$ using two-stage GMM estimator. Newey-West robust standard errors, 12 lags window. Number in square brackets is p-value for Wald test of hypothesis $H_{0}=0$. For D-test, number in square bracket is p-value for accepting estimation restrictions. Sample: 1960:1- 2004:1 unless otherwise indicated. Data source: Shimer (2006), Valletta (2005), BLS, BEA. 

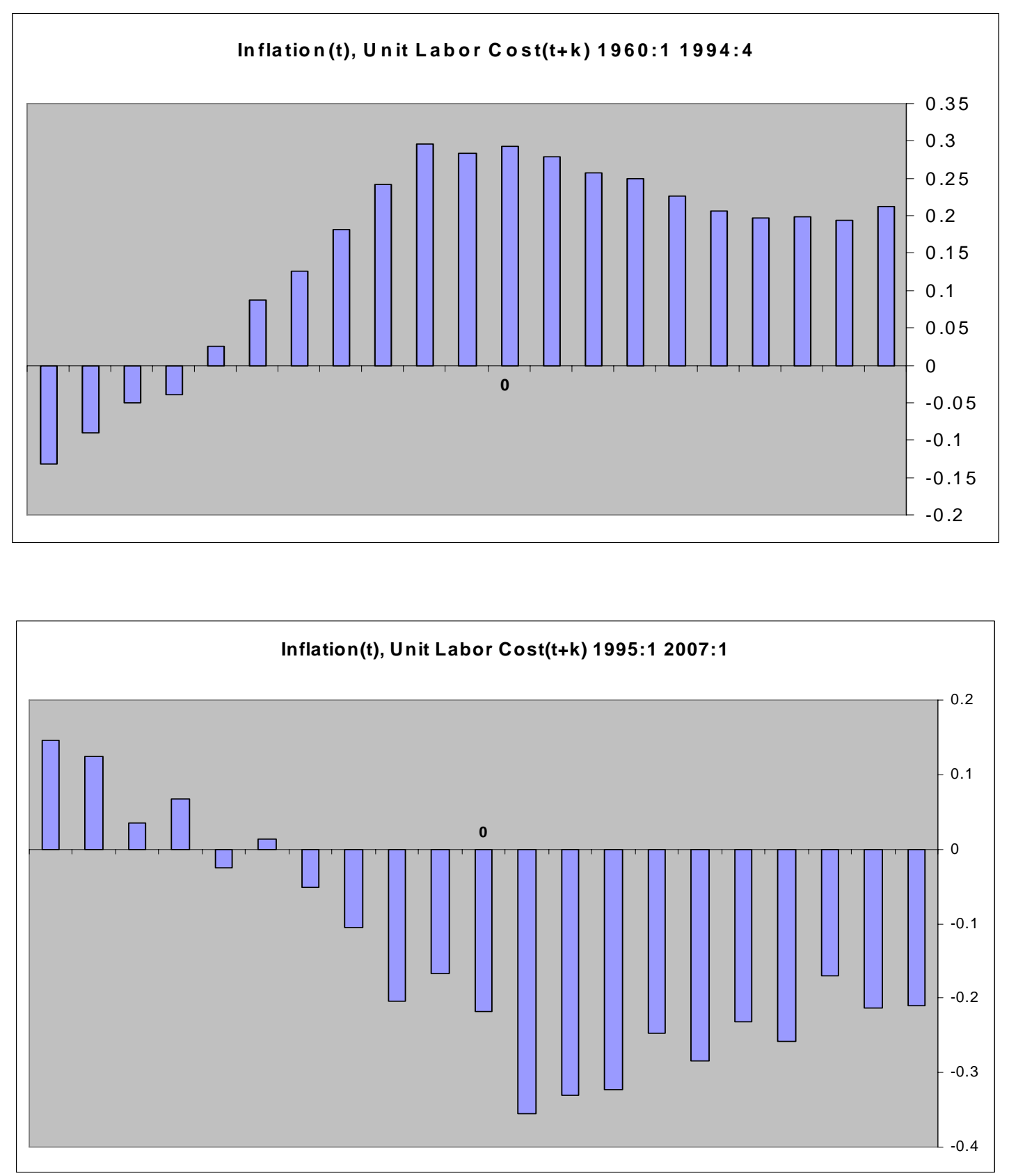

Figure 5: Cross-correlation Non-Farm Business Sector Price Deflator and Unit Labor Cost. 

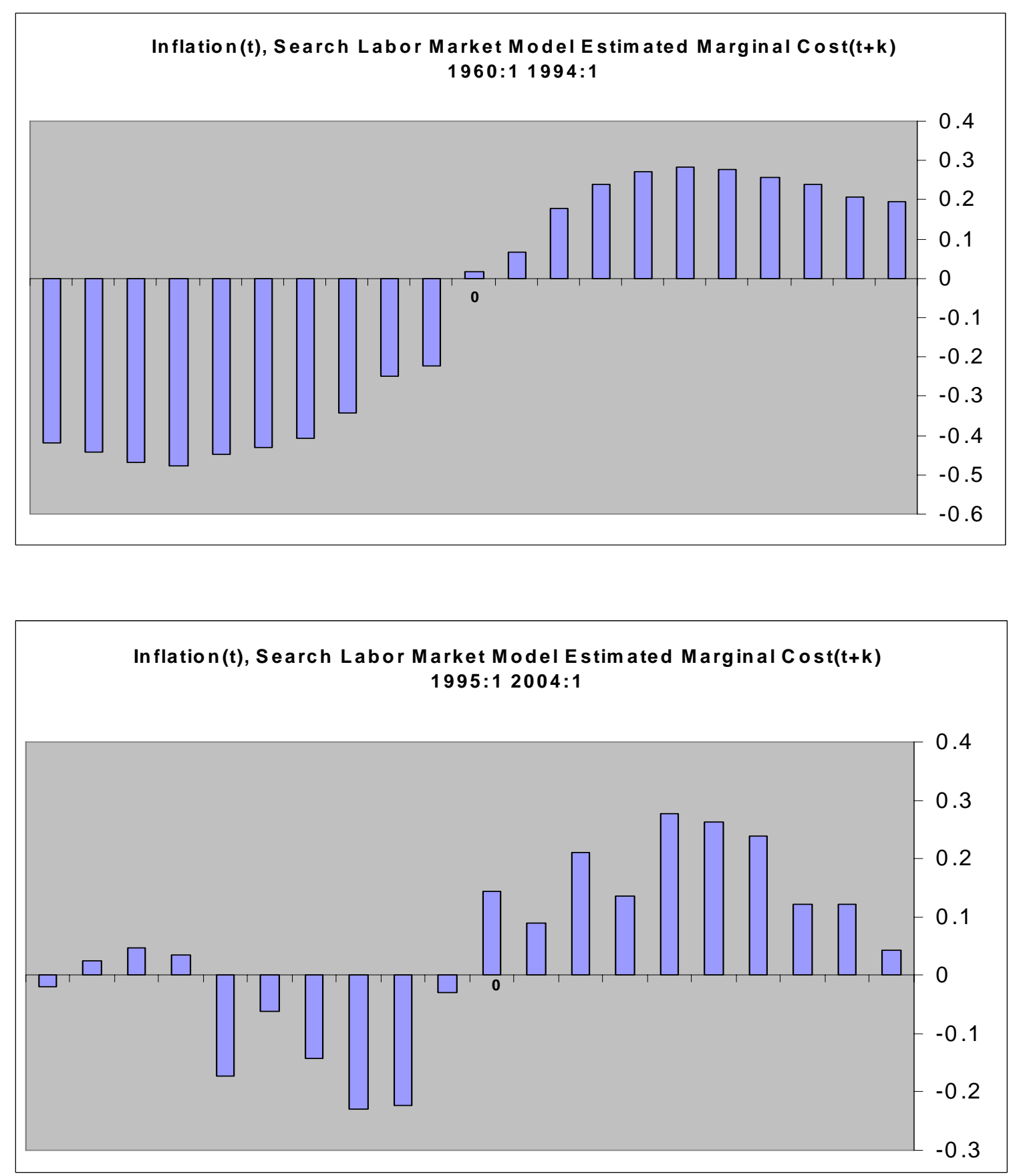

Figure 6: Cross-correlation Non-Farm Business Sector Price Deflator and search labor market model Marginal Cost estimated using Table 1 coefficients. 
Table 2: Estimates of the Phillips Curve - Cost Channel specification

\begin{tabular}{|c|c|c|c|c|c|c|c|}
\hline & $\beta_{0}$ & $\beta_{1}$ & $\beta_{2}$ & $\beta_{3}$ & $\beta_{4}$ & $\beta_{5}$ & $D-t e s t$ \\
\hline \multicolumn{8}{|c|}{ NFB Price Deflator } \\
\hline Restricted & $\begin{array}{l}0.874 \\
{[<0.001]}\end{array}$ & $\begin{array}{l}0.005 \\
{[0.126\rceil}\end{array}$ & 0 & 0 & $\begin{array}{l}0.099 \\
{[0.012]}\end{array}$ & 0 & \\
\hline Unrestricted & {$\left[\begin{array}{c}0.903 \\
{[<0.001]}\end{array}\right.$} & -0.016 & $\begin{array}{l}-0.024 \\
{[<0.001]}\end{array}$ & $\begin{array}{c}-0.003 \\
{[0.041]}\end{array}$ & $\begin{array}{c}0.092 \\
{[<0.001]}\end{array}$ & $\begin{array}{r}0.005 \\
{[<0.001]}\end{array}$ & $\begin{array}{l}131.43 \\
{[<0.001]}\end{array}$ \\
\hline
\end{tabular}

Estimates of the equation $\pi_{t}=\beta_{0} E_{t} \pi_{t+1}+\beta_{1} \widehat{m c}_{t}^{N K}+\beta_{2} \widehat{l p}_{t}+\beta_{3} \widehat{q}_{t}+\beta_{4} \widehat{i}_{t}+$ $\beta_{5} E_{t} \widehat{q}_{t+1}+\gamma \varepsilon_{a_{t}}$ where $\beta_{0}=\left\{[\beta]+\left[-\delta \frac{1}{M C_{s s}} \frac{1}{L P_{s s}}(1-\rho) \beta \frac{1}{q_{s s}} \kappa e^{\mu_{a}}\right]\right\}$ using twostage GMM estimator. Newey-West robust standard errors, 12 lags window. Number in square brackets is p-value for Wald test of hypothesis $H_{0}=0$. For D-test, number in square bracket is p-value for accepting estimation restrictions. Sample: 1960:1- 2004:1. Data source: Shimer (2006), Valletta (2005), BLS, BEA. 
Table 3: Estimates of the Phillips Curve - Lagged Inflation specification

\begin{tabular}{|c|c|c|c|c|c|c|c|}
\hline & $\beta_{0}$ & $\beta_{1}$ & $\beta_{2}$ & $\beta_{3}$ & $\beta_{4}$ & $\beta_{5}$ & $\beta_{6}$ \\
\hline \multicolumn{8}{|l|}{ NFB Pr ice Deflator } \\
\hline Restricted & $\begin{array}{l}0.665 \\
{[<0.001]}\end{array}$ & $\begin{array}{l}0.006 \\
{[0.039]}\end{array}$ & 0 & 0 & $\begin{array}{l}0.085 \\
{[<0.001]}\end{array}$ & 0 & $\begin{array}{l}0.222 \\
{[<0.001]}\end{array}$ \\
\hline Unrestricted & $\begin{array}{c}0.709 \\
{[<0.001]}\end{array}$ & $\begin{array}{r}-0.008 \\
{[0.050]}\end{array}$ & $\begin{array}{l}-0.007 \\
{[0.512]}\end{array}$ & $\begin{array}{l}-0.005 \\
{[0.005]}\end{array}$ & {$\left[\begin{array}{c}0.082 \\
{[<0.001]}\end{array}\right.$} & $\begin{array}{l}0.007 \\
{[<0.001]}\end{array}$ & $\begin{array}{c}0.187 \\
{[<0.001]}\end{array}$ \\
\hline
\end{tabular}

Estimates of the equation $\pi_{t}=\beta_{0} E_{t} \pi_{t+1}+\beta_{1} \widehat{m c}_{t}^{N K}+\beta_{2} \widehat{l p}_{t}+\beta_{3} \widehat{q}_{t}+\beta_{4} \widehat{i}_{t}+$ $\beta_{5} E_{t} \widehat{q}_{t+1}+\beta_{6} \pi_{t-1}+\gamma \varepsilon_{a_{t}}$ using two-stage GMM estimator. The specification includes the regressor $i_{t}$ rather than $r_{t}$ to allow explicitly for the existence of a cost channel. Newey-West robust standard errors, 12 lags window. Number in square brackets is p-value for Wald test of hypothesis $H_{0}=0$. The D-test rejects the restrictions with a p-value smaller than 0.1\%. Sample: 1960:12004:1. Data source: Shimer (2006), Valletta (2005), BLS, BEA. 
Table 4: Estimates of the Phillips Curve - Structural Parameters

\begin{tabular}{|c|c|c|c|c|c|c|}
\hline & $\beta$ & $\omega$ & $\rho$ & $\kappa$ & $\alpha^{\cos t}$ & $D-t e s t$ \\
\hline NFB Pr ice Deflator & & & & & \multirow{4}{*}{$\begin{array}{c}1.20 \\
{[<0.003]}\end{array}$} & \multirow[b]{4}{*}{$\begin{array}{c}2733.75 \\
{[<0.001]}\end{array}$} \\
\hline Restricted & $\begin{array}{l}0.962 \\
{[<0.001]}\end{array}$ & $\begin{array}{l}0.838 \\
{[<0.001]}\end{array}$ & 0 & 0 & & \\
\hline Restricted-Cost Channel & $\begin{array}{c}0.92 \\
{[<0.001]}\end{array}$ & {$\left[\begin{array}{l}0.856 \\
{[<0.001]}\end{array}\right.$} & 0 & 0 & & \\
\hline Unrestricted & $\begin{array}{c}0.96 \\
{[0.015]}\end{array}$ & {$\left[\begin{array}{c}0.86 \\
{[<0.001]}\end{array}\right.$} & $\begin{array}{c}0.36 \\
{[<0.001]}\end{array}$ & $\begin{array}{l}0.029 \\
{[0.073]}\end{array}$ & & \\
\hline
\end{tabular}

Structural estimates of the search-friction New Keynesian Phillips Curve using two-stage nonlinear GMM estimator. Newey-West robust standard errors, 12 lags window. Number in square brackets is p-value for Wald test of hypothesis $H_{0}=0$. For D-test, number in square bracket is $\mathrm{p}$-value for accepting estimation restrictions in 'Restricted' estimate. Sample: 1960:1- 2004:1. Data source: Shimer (2006), Valletta (2005), BLS, BEA. 


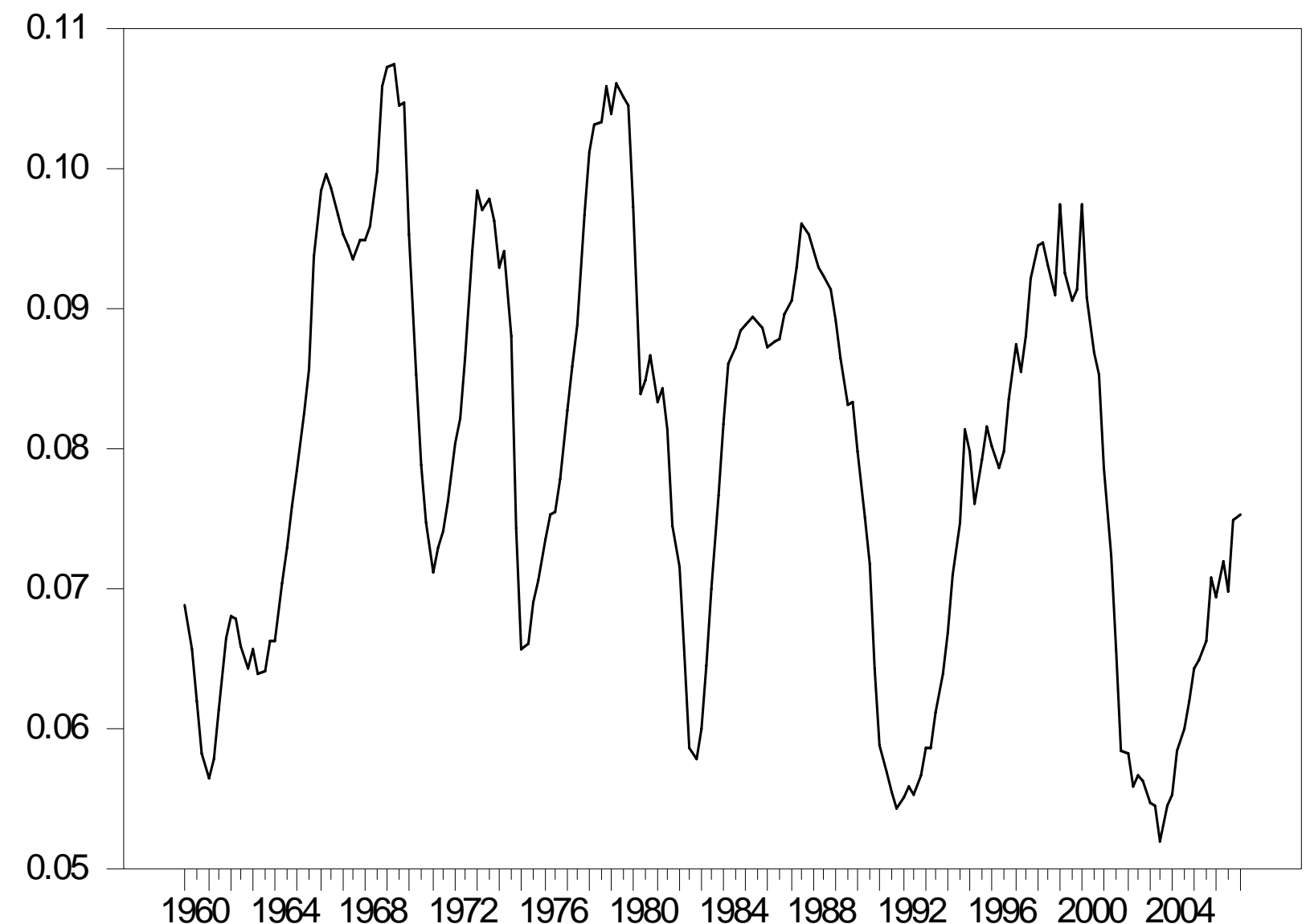

Figure 7: Estimated total cost of search as share of output. Non farm business sector. Scaling in percent. 